Portland State University

PDXScholar

2-25-1972

\title{
Application of Numerical Analysis to Root Locus Design of Feedback Control Systems
}

Steve William Justice

Portland State University

Follow this and additional works at: https://pdxscholar.library.pdx.edu/open_access_etds

Part of the Electrical and Computer Engineering Commons Let us know how access to this document benefits you.

Recommended Citation

Justice, Steve William, "Application of Numerical Analysis to Root Locus Design of Feedback Control Systems" (1972). Dissertations and Theses. Paper 379.

https://doi.org/10.15760/etd.379

This Thesis is brought to you for free and open access. It has been accepted for inclusion in Dissertations and Theses by an authorized administrator of PDXScholar. Please contact us if we can make this document more accessible: pdxscholar@pdx.edu. 
AN ABSTRACT OF THE THESS of Steve William Justice for the Master of Science in Appilied Science preserted pebruary 1972.

Title: Appliterton of Numerical Analysis to Root Locus Design of Feedback Control Systens.

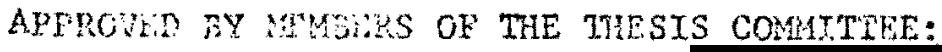

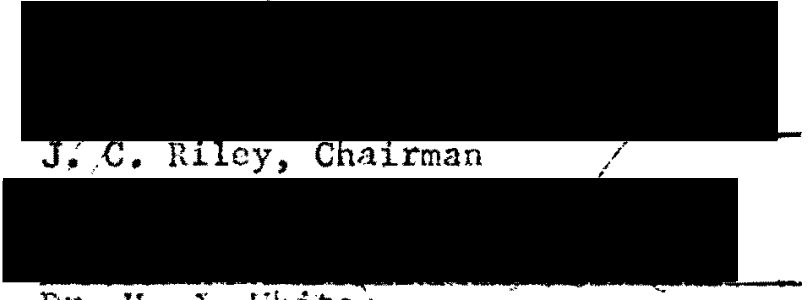

Dr. II. S. White:
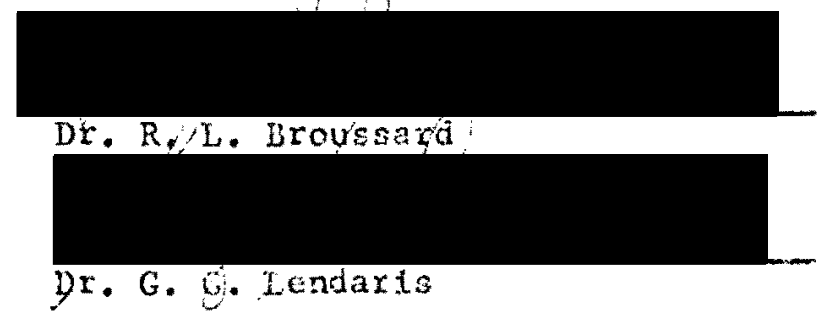

Keny practical problems in the field of engineering become so complex that they may be effectively solved only with the aid of a computer. An effective solution dcpends on the use of an efficient al rorithne Plotting root locus diagrans is such a problem. This thesis presents such an algorithm.

Rrot locus design of feedback control systems is a very powerful tool. Stability of systems under the influence of variables can be easily determined from the root locus diagram. For even moderately complex systems of the type found in practical applications, determination of the locus is extremely difficult if accuracy is required. The difficulty lies in the classical method of graphically determining the location of points on the locus by trial and error. Such a method canxot be ejificitly applied to a computer program. 
The text presents an original algorithm for plotting the root locus of a general system. The algorithm is derived using the combined methods of complex variable algebra and numerical analysis. For each abscissa desired a polynomial is generated. The real roots of this polynomial are the ordinate values for points on the root locus. Root finding methods from numerical analysis enable the solution of the problem to be one of convergent 1teration rather than trial and error.

Among the material presented is a computer program for solution of the general problem, an example of a completely analytic solution, and a table of solutions for more simple systems. The program inputs are the coefficients of the open loop transfer function and the range and increments of the real axis which are to be swept. The output lists the real and Imaginary components of all solution points at each increment of the sweep. Also 11sted are the magnitude and angle components of the solution point and the value of system gain for which this is a solution. For less complex problems, the method can be applied analytically. This may result in an explicit relation between the real and imaginary components of all solution points or even in a single expression which can be analyzed using the methods of analytic geometry.

As with any advance in the theory of problem solving, the ideas presented in the thesis are best applied in conjunction with previous solution methods. Specifically, an idea of the approximate location of the root locus can be obtained using sketching rules which are well 
known. The method presented here becomes much more efficient when even a rough approximation is known. Furthermore, the specific locations of system poles and zeros are not required, but can be helpful in planning areas in which to search for solutions. 
APPLICATION OF NUMERICAL ANALYSIS TO ROOT

LOCUS DESIGN OF FEEDBACK CONTROL SYSTEMS

by

STEVE WILLIAM JUSTICE

A thesis submitted in partial fulfillment of the requirements for the degree of

MASTER OF SCIENCE

In

APPLIED SCIENCE

Portland State University

1972 
TO THE OFFICE OF GRADUATE STUDIES:

The members of the committee approve the thesis of Steve William Just1ce presented February 25, 1972.

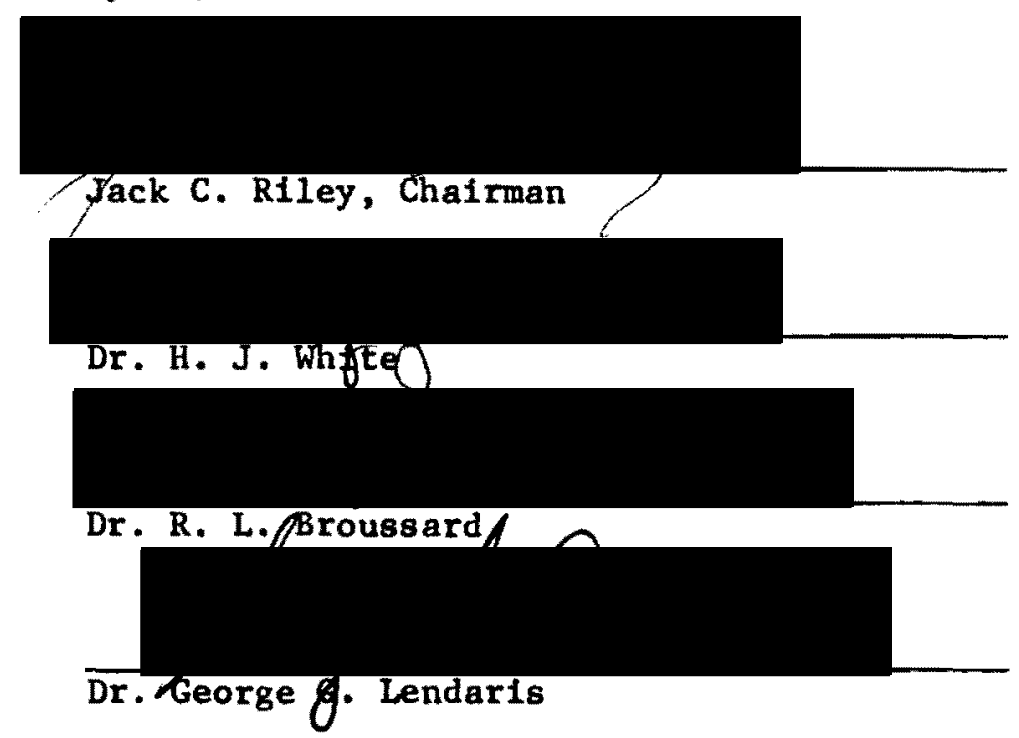

APPROVED:

Dr, Nan-Teh Hsu, Head, Department of Applied Sclence

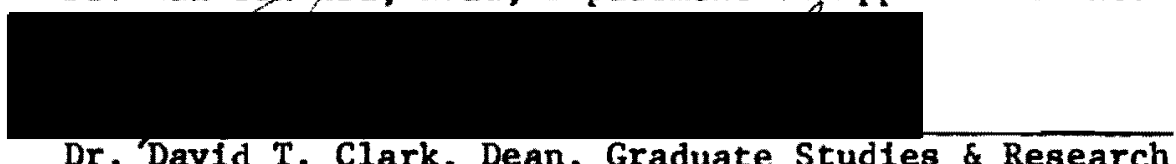


TABLE OF CONTENTS

PAGE

LIST OF TABLES . . . . . . . . . . . . . . . . 11

LIST OR FIGURES . . . . . . . . . . . . . . . 111

CHAPTER

I INTRODUCTION .................. 1

The Root Locus Method of Evans . . . . . . 2

Advances In Root Locus Design ......... 4

II DERIVATION OF THE BASIC EqUATION . . . . . . . 6

Application of $D(\omega)$ to Root Locus Plotting. . . 9

III ALGORITHSS . . . . . . . . . . . . 12

Synthet1c Division . . . . . . . . . 12

Shifting the Roots of a Polynomial . . . . . 14

Root Finding Methods ........... 16

Evaluating GH to Find K........... 17

The Computer Program . . . . . . . . . 21

IV AN ANALYTICAL METHOD . . . . . . . . . . . 31

An Example of the Analytic Method ....... 31

The General Analytic Solution . . . . . . 32

Concluston ............... . . 46

REFERENCES ...................... . . . 4 49 


\section{LIST OF TABLES}

TABLE

PAGE

I Program Input and Output for the Transfer Function $\mathrm{GH}=12(s+3) /\left(s^{4}+8 s^{3}+30 s^{2}+36 s\right) \ldots . . .$.

II Root Loci for Low Order Systems . . . . . . . . . 37 


\section{LIST OF FIGURES}

FIGURE

PAGE

1. The cannonical feedback control system ......

2. The computer program ..............

3. An approximate root locus for the transfer function

$$
\mathrm{GH}=\frac{12 \mathrm{~K}(\mathrm{~s}+3)}{\mathrm{s}\left(\mathrm{s}^{2}+6 \mathrm{~s}+18\right)(\mathrm{s}+2)} \text {.......... }
$$

4. The root locus for $G H=\frac{12 K(s+3)}{s\left(s^{2}+6 s+18\right)(s+2)} \ldots . .$.

5. The root locus for $\mathrm{GH}=\frac{\mathrm{K}(\mathrm{s}+3)}{\mathrm{s}(\mathrm{s}+2)\left(\mathrm{s}^{2}+6 \mathrm{~s}+25\right)}$....

6. a. The root locus for $\mathrm{GH}=K\left(8^{2}-2 u s+u^{2}+v^{2}\right)$

b. The root locus for $\mathrm{GH}=K\left(\mathrm{~s}^{2}+68+34\right) /\left(\mathrm{s}^{2}+8\right) .$. 


\section{CHAPTER I}

\section{INTRODUCTION}

The root locus method of analysis and synthesis of feedback control systems was introduced in 1949 by W. R. Evans.' Since that time it has become very popular. It is not difficult for an experienced person to sketch an approximate root locus diagram. For even moderate accuracy, however, the calculations involved become very time consuming. Computers and special devices can shorten computation time but the Inherent inefficiency of Evans' method cannot be corrected without a complete reversal of the approach to the problem.

The purpose of this paper is to present such an alternative approach. This method, developed expressly for digital computers, provides speed of computation and ease of programing. The method has been hinted at by some authors ${ }^{2}$ but the full scope of the analytical approach was not realized. Adaptation of the specific problem to the program presented in the third chapter is generally easier than to Evans' method since the characteristic equation need not be factored.

The method of solution derived in Chapter II also leads to an analytical solution of the problem. Equations can be derived relat-

'W. R. Evans, "Graphical Analysis of Control Systems," Trans. AIEE, vol. 68 (1949), PP. 765-777.

2Kenneth Stelglitz, "An Analytical Approach to Root Loc1," IRE Transactions on Automatic Control, Sept. 1961, Pp. 326-332. 
ing the ordinates to the abscissas of all solution points. Chapter IV contains an example of this method and a table of solutions for the more simple problems.

The Root Locus Method of Evans

The canonical feedback control system of Figure 1 has an open-

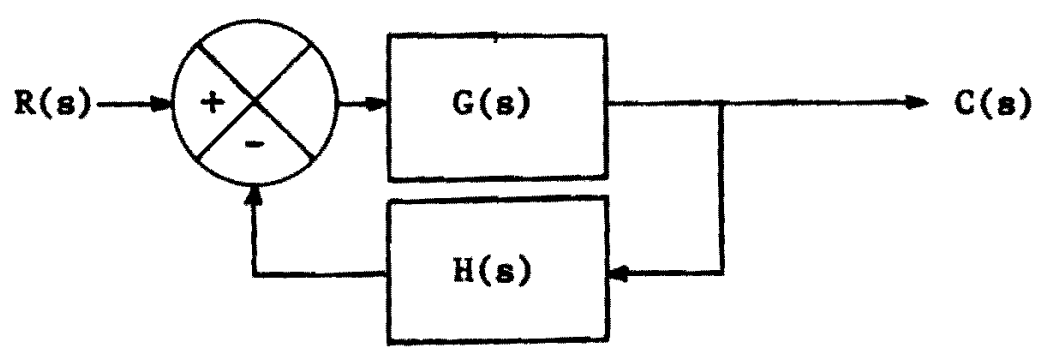

Figure 1. The canonical feedback control system.

loop transfer function which can be represented in factored form as

$$
G H=\frac{k \prod_{i=1}^{m}\left(s-z_{1}\right)}{\prod_{j=1}^{n}\left(s-p_{j}\right)}
$$

where $K$ is a constant which is independent of the complex variable $s=\sigma+j \omega$. Each $z_{1}$ represents a zero of the open-loop transfer function. There are $m$ of these any or all of which may be equal. There are also $n$ poles of equation 1.1 denoted by $p_{j}$. It is assumed that complex poles and zeros occur in conjugate palrs.

The closed-1oop trangfer function is

$$
\frac{C}{R}=\frac{G}{1+G H}
$$

The stability of the closed-loop system can be determined by the loca- 
tions in the s-plane of the poles of the closed-loop system. ${ }^{3}$ These poles are the solutions to the equation $\mathrm{GH}=-1$ or, from equation 1.1 ,

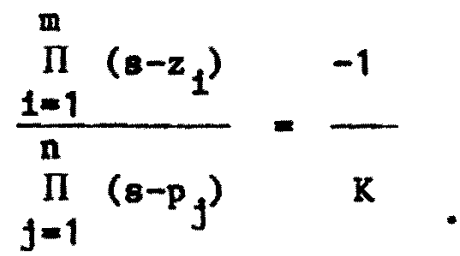

As $\mathrm{K}$ is varied from zero to infinity, the solutions of equation 1.3 move from the open-loop poles to the open-loop zeros. The path taken in the s-plane by these solutions is called the root locus.

The graphical method of Evans 18 based on the representation of each term $\left(8-8_{1}\right)$ as a vector in the $8-p$ lane. When treated as a vector equation, equation 1.3 may be separated into two equations, one relating the arguments of the vectors or the angle formed by the vectors with respect to the horizontal and one relating the magnitudes of the vectors.

$$
\begin{aligned}
& \sum_{1=1}^{m} \arg \left(s-z_{1}\right)- \sum_{j=1}^{n} \arg \left(s-p_{j}\right)=180(d) \\
& \frac{\prod_{i=1}^{m}\left|s-z_{1}\right|}{\prod_{j=1}^{n}\left|s-p_{j}\right|}=\frac{1}{|k|}
\end{aligned}
$$

Equation $1.4 \mathrm{a}$ is calculated in degrees with $\mathrm{d}$ odd if $\mathrm{K}$ is greater than zero and even if $K$ is less than or equal to zero. The points which are solutions of equation $1.4 \mathrm{a}$ define the root locus. These points

3E. P. Popov, The Dynamics of Automatic Control Systems, 1962, p. 241 . 
are found by a trial and error method. For this reason the number of calculations becomes excessive even for simple loci. Obviously, any computer program using this method must be very inefficient.

\section{Advances in Root Locus Design}

To reduce the number of calculations involved, sketching rules are presented in most texts. 4 Using these rules, and with experience, it is possible to sketch a relatively complex locus with a fair degree of accuracy. Use of a Spirule can reduce the Inaccuracy from $10 \%$ to about $1 \% .^{5}$ The Spirule simplifies computation of equations 1.4 by reducing the number of readings taken and the number of additions necessary.

The ESIAC, an electronic computer, was designed and built exclusively for this and related problems. 6 Programming was relatively easy and direct. Once programed the solution could be quickly obtained. 7 The Inaccuracy of the ESIAC as well as the expense of having a separate computer for a specific problem, Iimited its feasibility.

In the following chapters, methods will be derived for a oystematic solution of the general root locus problem. The characteristic equation is manipulated to find the solutions on the imaginary axis.

${ }^{4}$ Robert H. Cannon Jr., Dynamics of Physical Systems, 1967, pp. 653-655.

${ }^{5}$ Cannon, p. 651 .

6. L. Morgan and J. C. Looney, "Design of the ESIAC Algebraic Computer," IRE Transactions on Electronic Computers, vol. EC-10 No.3, Sept. 1961, p.524.

7 Morgan and Looney, p. 529. 
Methods for shifting the position of the imaginary axis give the method its generality. Numerical analysis provides the means for replacing the trial and error method with a directly convergent iterative scheme. Time is saved not only by reducing the number of calculations done by the computer but also by making the adaptation of a problem to the computer program very simple. 
CHAPTER II

DERIVATION OF THE BASIC EQUATION

Equation 1.3 can be expressed not only as a ratio of factors of the form $\left(8-8_{1}\right)$ but also as a ratio of two polynomials in 8 . The polynomlal form of equation 1.1 is

$$
G H=\frac{K \sum_{1=0}^{m} a_{1} s^{1}}{\sum_{h=0}^{n} b_{h} s^{h}}
$$

With this notation equation 1.3 becomes

$$
\frac{\sum_{h=0}^{m} a_{1}{ }^{1}}{\sum_{h=0}^{n} b_{h^{8}}}=-\frac{1}{K}
$$

These polynomials are unique for any given set of factors. 8 The coefflclents can be generated by multiplication of the factors. In the derivation which follows we wish to find solutions of equation 2.1 flrst for points on the Imaginary axis $(s=j \omega)$ and then for all points by generalizing the method to $s=\sigma+j \omega$

$$
\mathbf{b}: \mathbf{c}
$$

To simplify the notation, let $\sum_{i=a}$ mean the summation as 1 varies from a to $b$ in increments of $c$. For example,

$$
\sum_{1=1}^{14: 4} 1-1+5+9+13=28
$$

${ }^{8}$, R. Stoll and E. J. Wong, Linear Algebra, 1968, p. 185. 
and

$$
\sum_{1=0}^{11: 2} 1^{2}=0+4+16+36+64+100=220
$$

Also $f$ is used to designate an imaginary number. That $18, f=\sqrt{-1}$, $j^{2}=-1, j^{3}=-\sqrt{-1}=-j, j^{4}=1, j^{5}=j$, etc. Using the notation

above

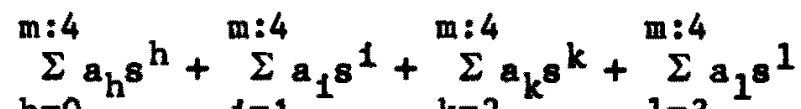

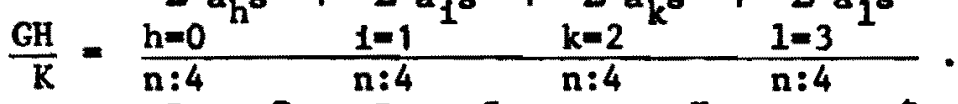

$$
\begin{aligned}
& \underset{p=0}{\sum} b_{p} p^{p}+\underset{q=1}{\sum} b_{q} q^{q}+\underset{r=2}{\sum} b_{r^{8}} s_{t=3}^{r} b^{8}
\end{aligned}
$$

Since $h=0,4,8, \ldots$, if $8=j \omega 3$ it follows that $8^{h}=\omega^{h}$. Also $1=1,5,9, \ldots$. Therefore, if $s=j \omega_{3} s^{1}=j \omega^{1}$. Similarly $8^{k}=-\omega^{k}$, $s^{1}=-\jmath \omega^{1}, s^{P}=\omega^{P}, s^{q}=j \omega^{q}, s^{r}=-\omega^{r}$, and $s^{t}=-j \omega^{t}$. Substituting $j \omega$ for $s$ in equation 2.2 and collecting the real and imaginary parts gives

$$
\frac{G H}{K}=\frac{\sum_{h=0}^{m: 4} a_{h} \omega^{h}-\sum_{k=2}^{m: 4} a_{k} \omega^{k}+j \sum_{1=1}^{m: 4} a_{1} \omega^{1}-j \sum_{l=3}^{m: 4} a_{1} \omega^{1}}{\sum_{p=0}^{n: 4} b_{p} \omega^{p}-\sum_{r=2}^{n: 4} b_{r} \omega^{r}+j \sum_{q=1}^{n: 4} b_{q} \omega^{q}-j \underset{t=3}{n: 4} b_{t} \omega^{t}} .
$$

To rationalize the denominator, the numerator is multiplied by the complex conjugate of the denominator. The resulting expression for the numerator is

$$
\begin{aligned}
& \left(\sum_{h=0}^{m: 4} a_{h} \omega^{h} \underset{k=2}{m: 4} a_{k} \omega^{k}\right)\left(\sum_{p=0}^{n: 4} b_{p} \omega^{p}-\sum_{r=2}^{n} b_{r} \omega^{r}\right) \\
& +\left(\sum_{1=1}^{m: 4} a_{1} \omega^{i}-\sum_{1=3}^{m: 4} a_{1} \omega^{1} \bigwedge_{q=1}^{n: 4} \sum_{q} \omega q-\sum_{t=3}^{n: 4} b_{t} \omega^{t}\right) \\
& +j\left(\sum_{1=1}^{m: 4} a_{1} \omega^{1}-\sum_{1=3}^{m: 4} a_{1} \omega^{1} \bigwedge_{p=0}^{n: 4} \sum_{p} b_{p}{ }_{p}^{p} \sum_{r=2}^{n: 4} b_{r} \omega^{r}\right) \\
& -j\left(\sum_{h=0}^{m: 4} a_{h} \omega^{h}-\sum_{k=2}^{m: 4} a_{k} \omega^{k}\right)\left(\sum_{q=1}^{n: 4} b_{q} \omega q-\sum_{t=3}^{\sum} b_{t} \omega^{t}\right) \text {. }
\end{aligned}
$$


Solutions to equation 2.1 must be real. The rationalized denominator of equation 2.2 must be real. Therefore if a solution is to be found for equation 2.1 , the expression for the numerator on the preceding page must be real. This implies that the imaginary part is equal to zero. Expanding the Imaginary part of the numerator gives an expression which shall be called the basic equation and notated as " $D(\omega)$ " In the text.

$$
\begin{aligned}
& D(\omega)=\sum_{h=0}^{m: 4} a_{h} \omega^{h} \underset{t=3}{n: 4} b_{t} \omega^{t}-\sum_{h=0}^{m: 4} a_{h} \omega^{h n} \sum_{q=1}^{n: 4} b_{q} \omega q
\end{aligned}
$$

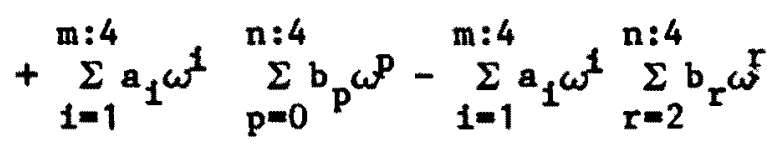

$$
\begin{aligned}
& +\sum_{k=2}^{m: 4} a_{k} \omega^{k} \underset{q=1}{\sum} \sum_{q} \omega^{q}-\sum_{k=2}^{m: 4} a_{k} \omega^{k} \underset{t=3}{\sum b_{t} b_{t}} \omega^{t} \\
& +\sum_{1=3}^{m: 4} a_{1} \omega^{1} \underset{r=2}{\sum: 4} b_{r} \omega^{r}-\sum_{1=3}^{m: 4} a_{1} \omega^{1} \underset{p=0}{\sum b_{p} b_{p}} \omega^{p}
\end{aligned}
$$

To simplify the expression the coefficients of 11 ke powers of $\omega$ are collected. This is done by noting that

$$
\begin{gathered}
\sum_{h=0}^{m: 4} a_{h} \omega^{h} \sum_{t=3}^{n: 4} b_{t} \omega^{t}=a_{0} \omega^{0_{b}} \omega_{3}^{3}+a_{4} \omega^{4} b_{3} \omega^{3}+a_{8} \omega^{\beta_{b}} \omega^{3}+\ldots \\
\quad+a_{0} \omega^{0_{b}} \omega^{7}+a_{4} \omega^{4} b_{7} \omega^{7}+\ldots \\
=a_{0} b_{3} \omega^{3}+\left(a_{4} b_{3}+a_{0} b_{7}\right) \omega^{7}+\left(a_{8} b_{3}+a_{4} b_{7}+a_{0} b_{11}\right) \omega^{11} \ldots
\end{gathered}
$$

and that for $1>m, a_{1}=0$ and for $1>n, b_{1}=0$. These simplifications, when applied to equation 2.3 result in the general form of the basic equation:

$$
D(\omega)=\left(-a_{0} b_{1}+a_{1} b_{0}\right) \omega+\left(a_{0} b_{3}-a_{1} b_{2}+a_{2} b_{1}-a_{3} b_{0}\right) \omega^{3}+\ldots
$$


The last term of equation 2.4 is

$$
\begin{aligned}
& (-1)^{k} a_{m} b_{n} \omega^{m+n} \text { if } m+n \text { is odd or } \\
& (-1)^{k} \quad\left(-a_{m-1} b_{n}+a_{m} b_{n-1}\right) \omega^{m+n-1} \text { if } m+n \text { is even. }
\end{aligned}
$$

The value of $k$ in the first case is $(m-n-1) / 2$. If $m+n$ is even, $k$ is equal to $(m-n) / 2$. It can be verified that if $d_{k}$ is the coefficient of $\omega^{k}$ in $D(\omega)$ then

$$
d_{k}=\left\{\begin{array}{l}
0 \text { for } k \text { even or } \\
\frac{k+1}{(-1)^{2}} \sum_{i=0}^{k}(-1)^{i} a_{i} b_{k-1} \text { for } k \text { odd. }
\end{array}\right.
$$

Application of $D(\omega)$ to Root Locus Plotting

The polynomial $D(\omega)$ has the general form

$$
D(\omega)=d_{1} \omega+d_{f^{3}} \omega^{3}+d_{5} \omega^{5}+\ldots+d_{p} \omega p
$$

where, from equation 2.4 , p equals $m+n$ or $m+n-1$ which ever is odd. The roots of $D(\omega)$ give the values of $\omega$ for which the imaginary part of equation 2.2 is zero and, therefore, the points on the imaginary axis which are solutions of equation 2.1 for some value of the gain constant $K$.

One of the roots is always zero since the coefficient of $\omega^{0}$ is zero. After generalization it will be shown that this is true of the polynomial $D(\omega)$ at every point along the real axis. (By restricting the polarity of $\mathrm{K}$, some or all of the real axis may be excluded from the 'root locus'). Extracting the zero root from equation 2.6 leaves

$$
D^{\prime}(\omega)=d_{1}+d_{3} \omega^{2}+d_{5} \omega^{4}+\ldots+d_{p} \omega^{p-1} .
$$


Substituting $\omega=\omega^{2}$ and $p^{l}=(p-1) / 2$ into equation 2.7 gives

$$
D^{\prime}\left(\omega^{\prime}\right)=d_{1}+d_{3} \omega^{\prime}+d_{5} \omega^{2}+\ldots+d_{p} \omega^{p^{\prime}} \text {. }
$$

Equation 2.8 is the basis for the solution of equation 2.1 by the computer program to be presented in Chapter III. The advantages are obvious. There are well known methods for finding the roots of polynomials. Only the positive real roots of equation 2.8 need be found since $\omega$ must be a real number. The order of the polynomial is always less than $(m+n) / 2$. For example, if $G(8) H(s)$ contains five zeros and seven poles, then $D^{\prime}\left(\omega^{\prime}\right)$ would be only a fifth order polynomial.

The root locus is symmetrical with respect to the real axis because for each positive real root of $D^{\prime}(\omega)$ there are two real roots of $D^{\prime}(\omega)$. That is, for each positive real $\omega, \omega= \pm \sqrt{\omega^{\prime}}$.

The roots of $D(\omega)$ give all the points along the imaginary axis which are solutions of equation 2.1 for some value of the gain constant $\mathrm{K}$. To find the solutions on some other vertical line, let $\mathrm{GH}=-1 / \mathrm{K}$ at $s=\sigma+j \omega$. Assume that the coefficients of $G(s+\sigma) H(s+\sigma)$ are known. Then the points on the root locus are the solutions for $G(s+\sigma) H(s+\sigma)$ at $s=j \omega$. These solutions can be found by generating the coefficients of $D(\omega)$ from those of $G(s+\sigma) H(s+\sigma)$. An algorithm for finding the coefficients of $G(s+\sigma) H(s+\sigma)$ from those of $G(s) H(s)$ is given in Chapter III. Graphically this amounts to shifting all the poles and zeros of GH $\sigma$ unfts to the right.

Plotting the root locus diagram involves repeating the steps below for a sufficient number of points on the real axis.

1. Find the coefficients of $G(s+\sigma) H(s+\sigma)$ from those of $G(s) H(s)$.

2. Solve for the coefficients of $D(\omega)$ using equation 2.5. 
3. Find the real roots of $D(\omega)$ preferably by finding the positive real roots of $D^{\prime}\left(\omega^{\prime}\right)$.

4. (Optional) Solve for the gain constant $\mathrm{K}$ at each real root of $D(\omega)$.

When applied in a computer program the method above is systematic and general. Algorithms for each of the steps will be presented in Chapter III. When working by hand or with a desk calculator it 1s suggested that as much advantage as possible be gained from experience and the sketching rules mentioned in the first chapter. The root finding methods in general require an iterative scheme. Thus, a first guess within $10 \%$ is extremely helpful. Also, it is an ald to know in advance approximately where along the real axis to look for branches of the root locus. For more simple problems $(m+n<6)$ it is advisable to use the analytic method proposed in Chapter IV. Using this method formulas can be derived to solve equation 2.1 by relating $\sigma$ to $\omega$ in a single expression. 
CHAPTER III

\section{ALGORITHMS}

The purpose of this chapter is to present algorithms for the operations necessary for the solution of equation 2.1 by the four step procedure presented In Chapter II. Fundamental to these algorithms is synthetic division of a polynomial. Shifting the roots of a polynomial is done by successive synthetic division as shown in section 2 . The third algorithm uses the Birge-Vieta method to find the real roots of a polynomial. Synthetic division is expanded to complex numbers to derive a simple method for evaluating $G(s) H(s)$ at the solution points of equation 2.1 in order to find the value of $K$ which gives this solution. The last section of this chapter presents a computer program which combines the algorithms and efficiently calculates the data necessary for plotting root locus diagrams.

\section{Synthetic Division}

Synthetic division is a term applied to a shorthand method of dividing a polynomial by a Iinear factor. Kunz derives the method using a mathematical scheme. ${ }^{9}$ The derivation given here is basically the same except where notation has been altered to conform with the present text.

${ }^{9}$ Kaiser S. Kunz, Numerlcal Analysis, 1957, pp. 19,20. 
Consider the following set of polynomials in $x$ :

$$
\begin{aligned}
P_{0}(x) & =a_{m} \\
P_{1}(x) & =x P_{0}(x)+a_{m-1} \\
& : \\
& \cdot \\
P_{k}(x) & =x P_{k-1}(x)+a_{m-k} \\
& : \\
& \cdot \\
P_{m}(x) & =x P_{m-1}(x)+a_{0} .
\end{aligned}
$$

Multiplying each equation by $x^{m-k}$ and adding the resulting $m+1$ equations gives a single polynomial of the form

$$
\begin{aligned}
& P_{m}(x)=a_{m} x^{m}+a_{m-1} x^{m-1}+\ldots+a_{0} \\
& P_{m}(x)=\sum_{k=0}^{m} a_{k} x^{k} .
\end{aligned}
$$

Since the evaluation of equation 3.2 requires calculation of powers of $x$, it is generally easier to evaluate $P_{m}(x)$ using equations 3.1 . When calculated in order of increasing values of $k$, each equation has only one unknown. A convenient scheme for arranging hand calculations is shown below:

$$
\begin{array}{lllllll}
x / & a_{m} & a_{m-1} & a_{m-2} & \cdots & a_{1} & a_{0} \\
& x P_{0} & x P_{1} & \cdots & x P_{m-2} & x P_{m-1} \\
\hline P_{0} & P_{1} & P_{2} & \cdots & P_{m-1} & P_{m}(x)
\end{array}
$$

Working from left to right, each $P_{k}$ is calculated by adding the values $a_{m-k}$ and $x P_{k-1}$ above it. 
Algorithm 3.1: Synthetic Division

Initial conditions: Let $a_{0}, a_{1}, \ldots, a_{m}$ be the coefficients of the polynomial $P_{m}(x)$ as in equation 3.2 . Let $x_{0}$ be the value at Which $P_{m}(x)$ is to be evaluated.

A3.1.1. Let $P_{0}=a_{m}$ and $k=0$.

A3.1.2. Increase $k$ by 1 .

A3.1.3. Let $P_{k}=x_{0} P_{k-1}+a_{m-k}$.

A3.1.4. If $k=\mathfrak{m}$, stop. Otherwise go back to step A3.1.2.

Results: The value of $P_{m}(x)$ at $x=x_{0}$ has been found.

Shifting the Roots of a Polynomial

The first step in the method of Chapter II for plotting root locus diagrams is to find the coefficlents of $G(8+\sigma) H(8+\sigma)$. Algorithm 3.2 is developed to accomplish this step.

The first derivatives of equations 3.1 are

$$
\begin{aligned}
P^{\prime}{ }_{0}(x) & =0 \\
P^{\prime}{ }_{1}(x) & =P_{0}(x) \\
P_{2}^{\prime}(x) & =x P^{\prime}{ }_{1}(x)+P_{1}(x) \\
& \vdots \\
& \cdot \\
P_{k}^{\prime}(x) & =x P^{\prime}{ }_{k-1}(x)+P_{k-1}(x) \\
& \cdot \\
& \cdot \\
P^{\prime}{ }_{m}(x) & =x P^{\prime}{ }_{m-1}(x)+P_{m-1}(x) .
\end{aligned}
$$

These values can be calculated simply by extending the diagram on page 13. Continuing this process $m+1$ times and dropping the zero 
terms on the right produces a series of synthetlc divisions the rightmost terms of which are $P_{m}\left(x_{0}\right), P_{m}^{\prime}\left(x_{0}\right), P_{m}^{\prime \prime}\left(x_{0}\right) / 2 !, \ldots, P_{m}^{(m)}\left(x_{0}\right) / m l$. Taylor's serles for shtfting a polynomial is

$$
P\left(x+x_{0}\right)=P\left(x_{0}\right)+x P^{\prime}\left(x_{0}\right)+x^{2} P^{\prime \prime}\left(x_{0}\right) / 2 !+\ldots+x^{m p m i n}\left(x_{0}\right) \cdot 10
$$

The coefficients are the same as those found by the extended synthetic division. Let $P_{3}(x)=x^{3}-6 x^{2}+8 x-5$. The solution for the coefficients of $\mathrm{P}_{3}(\mathrm{x}+3)$ would be calculated as shown below:

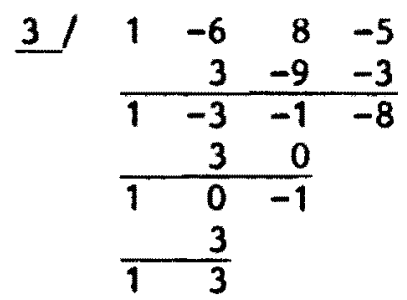

$$
P_{3}(x+3)=x^{3}+3 x^{2}-x-8
$$

Algorithm 3.2: Shifting The Roots of a Polynomial

Initial conditions: Let $P_{m}(x)=\sum_{k=0}^{m} a_{k} x^{k}$ be the given polynomial. Let $x_{0}$ be the amount by which $P_{m}(x)$ is to be shifted.

A3.2.1. Let $k=m+1,1=m+1$, and $a_{m+1}=0$.

A3.2.2. Decrease 1 by one.

A3.2.3. Decrease $k$ by one.

A3.2.4. Let $a_{k}=x_{0} a_{k+1}+a_{k}$.

A3.2.5. If $k$ is greater than $m-1$ go back to A3.2.3. Otherwise continue. A3.2.6. Let $k=m+1$. If $i$ is positive go back to A3.2.2. Otherwise stop.

Results: The coefficients of $P_{m}\left(x-x_{0}\right)$ are $a_{m}, a_{m-1}, \ldots, a_{0}$.

10 H. P. Westman, ed., Reference Data For Radio Engineers, 4th ed. 1967, p. 1084 . 
Root Finding Methods

The third step of the method outlined in Chapter II calls for finding the roots of $D^{\prime}\left(\omega^{\prime}\right)$. Many good methods for extracting the roots of a general polynomial may be found in the 1iterature. Only the positve real roots need be found. This allows for a great deal of simplification since more complex methods used for extracting complex roots need not be used. Descarte's rule of signs ${ }^{11}$ will determine whether or not positive roots exist. If the order of $D^{\prime}\left(\omega^{\prime}\right)$ is four or less, general equations may be employed to find the roots. ${ }^{12,13}$ In general, an iterative scheme must be used. The algorithm of this section is based on the Birge-Vieta method. 14

Let $P_{m}(x)$ be a polynomial of order $m$. If $x_{1}$ is a sufficiently close approximation to a root of $P(x)$ then

$$
x_{1+1}=x_{1}-\frac{P_{m}\left(x_{1}\right)}{P_{m}^{\prime}\left(x_{1}\right)}
$$

is a closer approximation. Using synthetic division as prescribed in the previous section, $P_{m}(x)$ and $P^{\prime}{ }_{m}(x)$ may be calculated and substituted into equation 3.3 . When the change in $x$ from one iteration to another is sufficiently small the method may be terminated. If no real roots exist, or under unusual circumstances, the method can continue

${ }^{11}$ Ralph H. Pennington, Introductory Computer Methods and Numerical Analysis Second Edition, 1970, p. 299.

12 Kaj L. Nielson, College Mathematics, 1958, pp. 102,164.

$$
\begin{aligned}
& { }^{13} \text { Kunz, p. } 33 . \\
& { }^{14} \text { Kunz, p. } 22 .
\end{aligned}
$$


endlessly without converglng. Thus some upper bound on the number of Iterations must be set.

Algorithm 3.2: Finding the Roots of a Polynomial

Initial conditions: Let $P_{m}(x)=\sum_{k=0}^{m} a_{k} x^{k}$ be the given polynomial.

Let $y$ be an approximation to a root of $P_{m}(x)$.

A3.3.1. If a $=0$ then stop since 0 is a root. Otherwise continue.

A3.3.2. If $m=2$ then $y_{1,2}=\left(-a_{1} \pm \sqrt{a_{1}{ }^{2}-4 a_{0} a_{2}}\right) /\left(2 a_{2}\right)$ are roots.

A3.3.3. Let $e_{0}=f_{0}=a_{0}$, and $f=t=0$.

A3.3.4. Increase $j$ by one. Let $e_{f}=a_{j}+y e_{j-1}$ and let $f_{j}=e_{j}+y f_{f-1}$.

A3.3.5. If $f=$ m continue. Otherwise go back to A3.3.4.

A3.3.6. If $e_{m} 18$ sufficiently small, stop. If not, let $y=y-\Delta y$

Where $\Delta y=e_{m} / f_{m-1}$. Increase $t$ by one.

A3.3.7. If $t$ is excessively large, stop. Otherwise go to A3.3.4.

Results: a. Zero was a root. The remaining roots may be found

by applying the algorithm to the polynomial after removing $a_{0}$

and reducing the power of each term of the original polynomial.

b. Both roots of the second order polynomial were found.

c. One root was found. The remaining roots may be found

by applying the algorithm to the polynomial with coefficient:

$\mathbf{e}_{\mathbf{k}} \cdot$

d. No root was found. The roots may all be complex.

Evaluating $\mathrm{GH}$ to Find $\mathrm{K}$

It is necessary in order to solve equation 2.1 completely to determine the value of the gain constant $K$ at the points which have been found ss solutions using the method presented in Chapter II. 
From equation 2.1

$$
K=-\frac{1}{G(s) H(s)}=-\frac{1}{G(\sigma+j \omega) H(\sigma+j \omega)}
$$

It is possible to extend the method of synthetic division to complex numbers. However, since the coefficlents of $\mathrm{G}(8+\sigma) \mathrm{H}(8+\sigma)$ are known, It 18 easier to consider only pure Imaglnary numbers. That is, evaluation of $G(\sigma+j \omega) H(\sigma+j \omega)$ can be done by evaluating $G(s+\sigma) H(s+\sigma)$ at $\mathrm{s}=\mathrm{j} \omega$.

Equations 3.1 are 1 isted below with $x$ replaced by $f \omega$ :

$$
\begin{aligned}
P_{0} & =a_{m} \\
P_{1} & =j \omega P_{0}+a_{m-1} \\
P_{2} & =j \omega P_{1}+a_{m-2} \\
& \vdots \\
& \cdot \\
P_{k} & =j \omega P_{k-1}+a_{m-k} \\
& : \\
& : \\
P_{m} & =j \omega P_{m-1}+a_{0}
\end{aligned}
$$

Substituting $P_{0}$ into $P_{1}, P_{1}$ into $P_{2}$ etc. gives

$$
\begin{aligned}
P_{0} & =a_{m} \\
P_{1} & =j \omega a_{m}+a_{m-1} \\
P_{2} & =j \omega\left(j \omega a_{m}+a_{m-1}\right)+a_{m-2} \\
& =a_{m-2}-\omega^{2} a_{m}+j \omega a_{m-1} \\
P_{3} & =j \omega\left(a_{m-2}\right. \\
& \left.=\omega^{2} a_{m}+j \omega a_{m-1}\right)+a_{m-3} \\
& =a_{m-3}-\omega^{2} a_{m-1}+j \omega\left(a_{m-2}-\omega^{2} a_{m}\right)
\end{aligned}
$$


Separating the real and Imaginary parts of $P_{k}$, denoted as $\operatorname{Re}\left(P_{k}\right)$ and $\operatorname{Im}\left(P_{k}\right)$ respectively, gIves the necessary recurrence relations for the synthetic division of a polynomial by a purely imaginary number.

$$
\begin{aligned}
& \operatorname{Re}\left(P_{0}\right)=a_{m} \quad \operatorname{Im}\left(P_{0}\right)=0 \\
& \operatorname{Re}\left(P_{1}\right)=a_{m-1} \quad \operatorname{Im}\left(P_{1}\right)=\omega \operatorname{Re}\left(P_{0}\right) \\
& \operatorname{Re}\left(P_{2}\right)=a_{m-2}-\omega^{2} \operatorname{Re}\left(P_{0}\right) \quad \operatorname{Im}\left(P_{2}\right)=\omega \operatorname{Re}\left(P_{1}\right) \\
& \text { • } \\
& \text { • } \\
& \operatorname{Re}\left(P_{k}\right)=a_{w-k}-\omega^{2} \operatorname{Re}\left(P_{k-2}\right) \quad \operatorname{Im}\left(P_{k}\right)=\omega \operatorname{Re}\left(P_{k-1}\right) \\
& \text { : } \quad \text { : } \\
& \operatorname{Re}\left(P_{m}\right)=a_{0}-\omega^{2} \operatorname{Re}\left(P_{m-2}\right) \quad \operatorname{Im}\left(P_{m}\right)=\omega \operatorname{Re}\left(P_{m-1}\right)
\end{aligned}
$$

The transer function in general is a ratio of two polynomials. Therefore, two polynomials must be evaluated using the relations above. The result is

$$
G H=\frac{\operatorname{Re}\left(P_{m}\right)+j \operatorname{Im}\left(P_{m}\right)}{\operatorname{Re}\left(P_{n}\right)+j \operatorname{Im}\left(P_{n}\right)} .
$$

The subscripts $m$ and $n$ are used to denote the last terms of the synthetic division operation on the numerator and denominator polynomials respectively. The magnitude of $\mathrm{GH}$ denoted $|\mathrm{GH}|$ is

$$
\begin{aligned}
|G H| & =\sqrt{\frac{\left[\operatorname{Re}\left(P_{m}\right)\right]^{2}+\left[\operatorname{Im}\left(P_{m}\right)\right]^{2}}{\left[\operatorname{Re}\left(P_{n}\right)\right]^{2}+\left[\operatorname{Im}\left(P_{n}\right)\right]^{2}}} \\
& =\sqrt{\frac{\left[\operatorname{Re}\left(P_{m}\right)\right]^{2}+\omega^{2}\left[\operatorname{Re}\left(P_{m-1}\right)\right]^{2}}{\left[\operatorname{Re}\left(P_{n}\right)\right]^{2}+\omega^{2}\left[\operatorname{Re}\left(P_{n-1}\right)\right]^{2}}}
\end{aligned}
$$

Note that in the recurrence relations 3.4 above and from the values 
needed to solve equation 3.6 , the Imaginary parts of the $P_{k}$ in equations 3.4 need not be calculated.

Finally, it must be determined whether $\mathrm{GH}$ is positive or negative. It has been determined that $G H$ is real. Considering $P_{m}$ and $P_{n}$ as vectors in equation 3.5 leads to the deduction that elther vectors $\mathrm{P}_{\mathrm{m}}$ and $P_{n}$ have the same direction or they are in exactly opposite directions. In the first case the angle of the vector GH is zero and GH is positive. In the second case the angle of $\mathrm{GH}$ is 180 degrees and $\mathrm{GH} 1 \mathrm{~s}$ negative. In the first case $\operatorname{Re}\left(P_{m}\right)$ and $\operatorname{Re}\left(P_{n}\right)$ have the same ign and in the second case they have opposite signs. Define the following function:

$$
\operatorname{sgn}(y)=\left\{\begin{array}{l}
+1 \text { if } y \text { is positive or zero. } \\
-1 \text { if } y \text { is negative. }
\end{array}\right.
$$

Then the following relation holds and is the equation solved by algorithm 3.4 :

$$
-\frac{1}{K}=G H=\operatorname{sgn}\left[\operatorname{Re}\left(P_{m}\right) \operatorname{Re}\left(P_{n}\right)\right] \sqrt{\frac{\left[\operatorname{Re}\left(P_{m}\right)\right]^{2}-\omega^{2}\left[\operatorname{Re}\left(P_{m-1}\right)\right]^{2}}{\left[\operatorname{Re}\left(P_{n}\right)\right]^{2}-\omega^{2}\left[\operatorname{Re}\left(P_{n-1}\right)\right]^{2}}} .
$$

Agor1thm 3.4: Evaluating $\mathrm{K}$

Initial conditions: Let $a_{m}, a_{m-1}, \ldots, a_{0}$ be the numerator coefficients and $b_{n}, b_{n-1}, \ldots, b_{0}$ be the denominator coefficients of $\mathrm{GH}$. Let $\omega$ be a real root of $D(\omega)$.

A3.4.1. Let $P_{0}=a_{m}, P_{1}=a_{m-1}$, and $1=1$.

A3.4.2. Increase 1 by one.

A3.4.3. Let $P_{1}=a_{m-1}-\omega^{2} P_{1-2}$.

A3.4.4. If 1 is less than mo back to A3.4.2. Otherwlse go to A3.4.5. A3.4.5. Let $\mathrm{u}=\omega^{2} \mathrm{P}_{\mathrm{m}-1}$.

A3.3.6. Let $K=\operatorname{sgn}\left(P_{m}\right) \sqrt{u+P_{m}^{2}}$. 
A3.4.7. Let $1=1, P_{0}=b_{n}, P_{1}=b_{n-1}$.

A3.4.8. Increase 1 by 1 .

A3.4.9. Let $P_{1}=a_{n-1}-\omega^{2} P_{1-2}$.

A3.4.10. If 1 is 1 ess than $n$ go to $\mathrm{A3.4.8.} \mathrm{Otherwise} \mathrm{continue.}$

A3.4.11. Let $u=\omega^{2} \mathrm{p}_{\mathrm{n}-1}^{2}$.

A3.4.12. Let $K=-\operatorname{sgn}\left(P_{n}\right) \sqrt{u+P_{n}^{2}} / K$

Results: The value of $K$ at $s=a+j \omega$ which solves equation 2.1 has been found.

The Computer Program

To complete the chapter on algorithms a computer program is presented. The program is complete and operational. It is set up to do a linear sweep or a series of linear sweeps along the real axis in the 8-plane. The output consists of the real and imaginary parts of each solution point, its magnitude and direction from the positive real axis, and the value of $\mathrm{K}$ which gives this solution. For a given abscissa all ordinates which solve equation 2.1 are found. Solutions for $\mathrm{K}$ less than zero are omitted by convention.

Figure 2 is a listing of the program. The following breakdown will ald in understanding the order in which the problem is solved. Lines Purpose

100-185 Preliminary operations including reading data and printing

190-200 column headings for the output.

580-585

705-710

Control of the sweep along the real axis.

$205-280$

Algorithm 3.2 . 


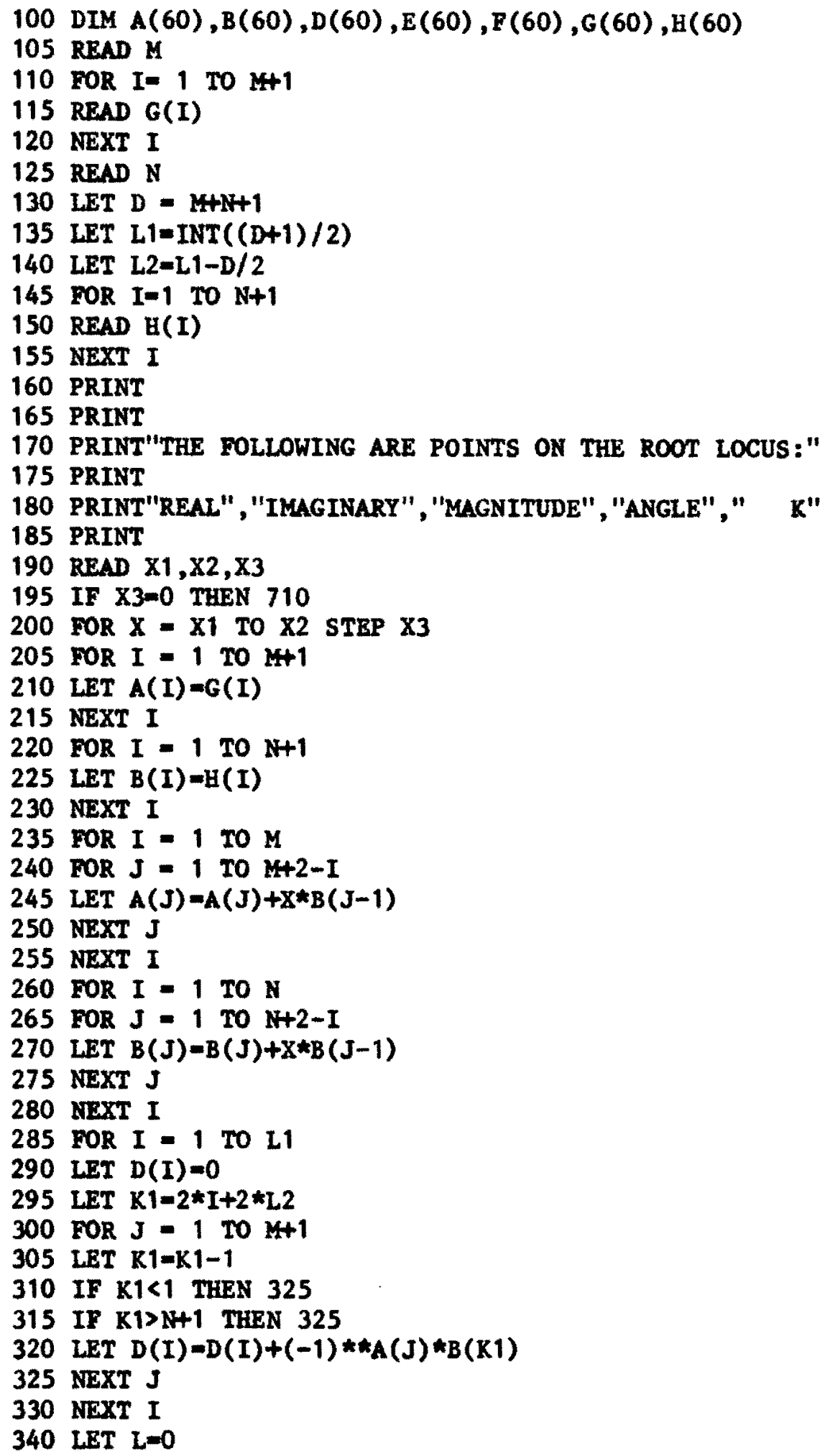

Figure 2. The program 1isting. 


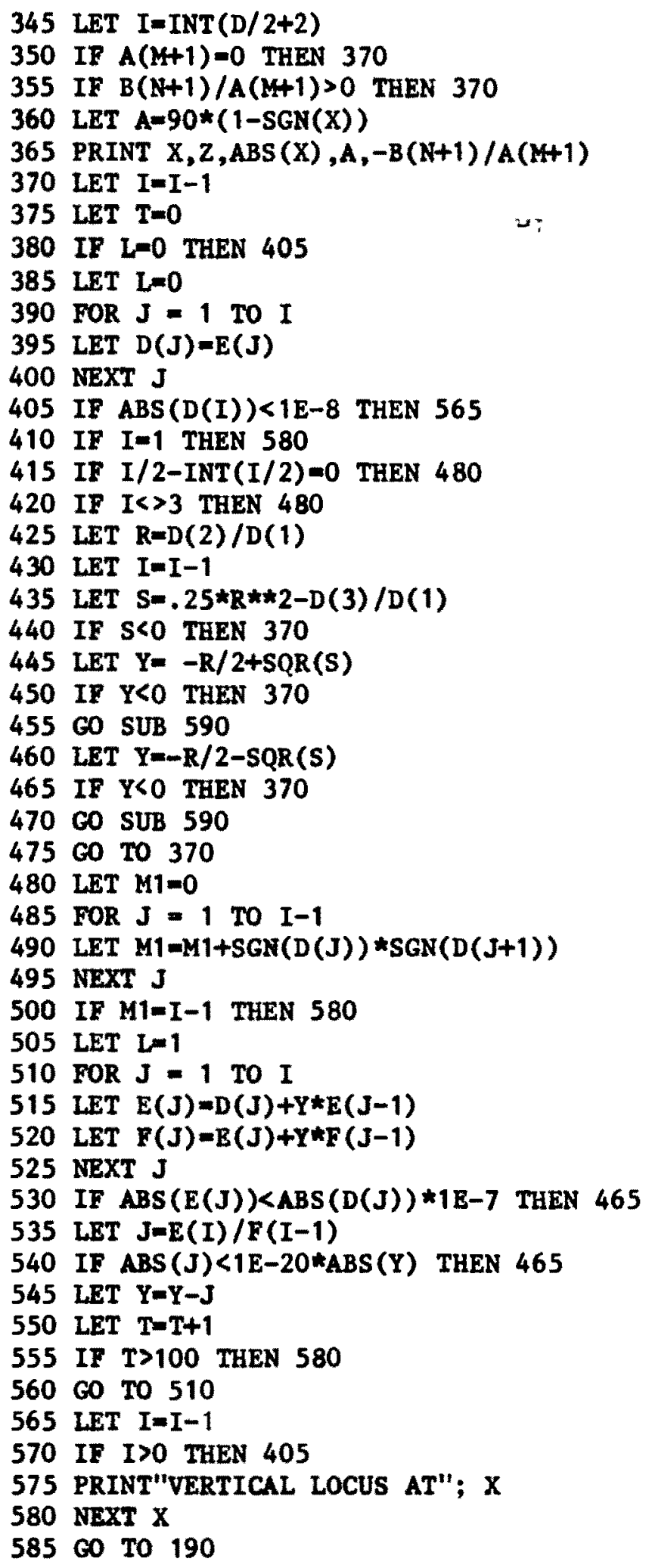

Figure 2. (continued). 


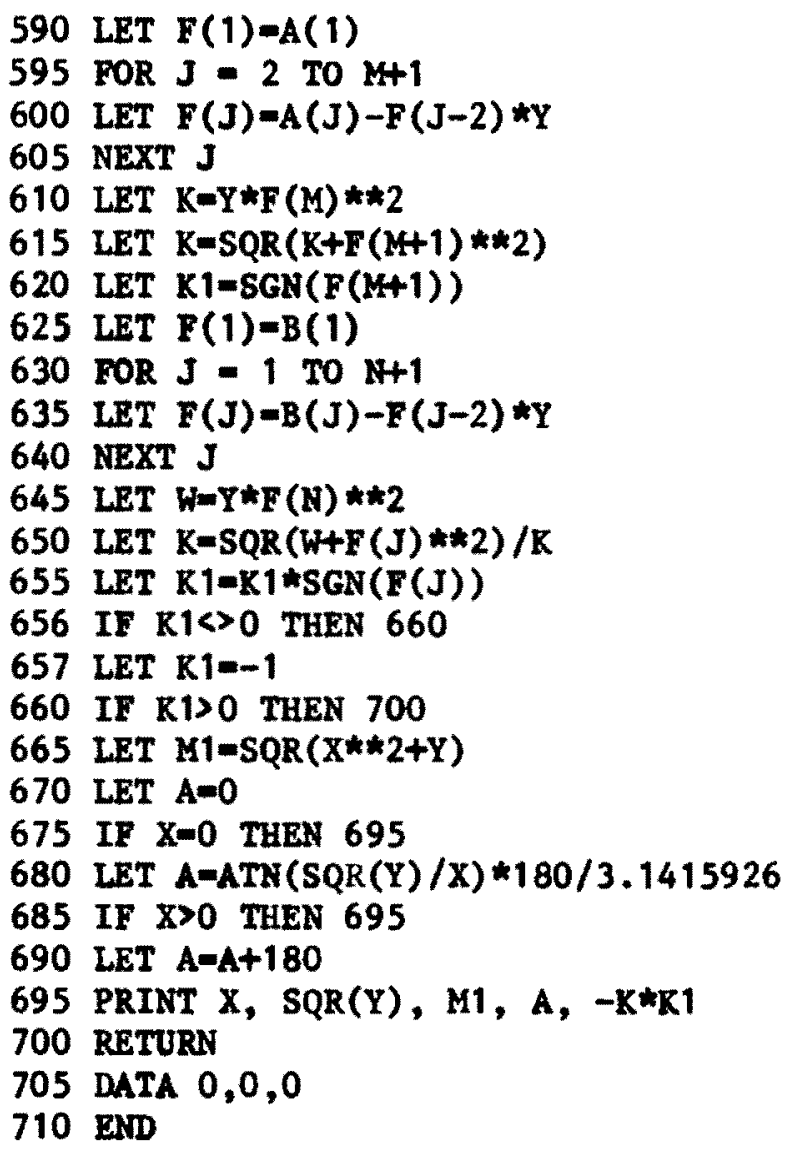

Figure 2. (continued). 
$\underline{\text { Lines }}$

Purpose

285-330

Finding the coefficients of $D(\omega)$.

$340-365$

Determining $\mathrm{K}$ for the point on the axis.

$370-575$

Finding the roots of $D(\omega)$.

$480-500$

Eliminating polynomials with no positve roots by Decarte's Rule.

$505-560$

Algorithm 3.3.

$590-700$

Algorithm 3.4 .

The input to the program is as follows:

10 DATA $m, a_{m}, a_{m-1}, \ldots, a_{0}$

20 DATA $n, b_{n}, b_{n-1}, \ldots, b_{0}$

30 DATA $x_{11}, x_{21}, x_{31}, x_{12}, x_{22}, x_{32}, \ldots, x_{1 k}, x_{2 k}, x_{3 k}$

where the root locus for the transfer function

$$
G H=\frac{K \sum_{1=0}^{m} a_{1} s^{1}}{\sum_{h=0}^{n} b_{h} s^{h}}
$$

Is to be found between $x_{11}$ and $x_{21}$ in steps of $x_{31}$ and from $x_{12}$ to $x_{22}$ In steps of $x_{32}$ etc.

Table I is a listing of the output of this program for the transfer function

$$
\mathrm{GH}=\frac{12 \mathrm{~K}(\mathrm{~s}+3)}{s\left(s^{2}+6 s+18\right)(s+2)}=\frac{K(12 s+36)}{s^{4}+8 s^{3}+30 s^{2}+36 s} .
$$

Using the sketching rules, a rough 1dea of the location of the locus can be determined. This is shown in figure 3. It is seen that the sweep should go from approximately -5 to +1 . For good results in one run, a step of 0.1 is chosen. The Input to the program is 
TABLE I

PROGRAM INPUT AND OUTPUT FOR GH $=12(8+3) /\left(8^{4}+88^{3}+30 s^{2}+368\right)$

10 DATA $1,12,36$

20 DATA $4,1,8,30,36,0$

30 DATA $-5,1,0.1$

RUN

THE FOLLOWING ARE POINTS ON THE ROOT LOCUS:

REAL

IMAGINARY MAGNITUDE

ANGLE

$\mathbf{K}$

\begin{tabular}{|c|c|c|c|c|}
\hline $\begin{array}{l}-5 \\
-4.9 \\
-4.8 \\
-4.7 \\
-4.6 \\
-4.5 \\
-4.4 \\
-4.3 \\
-4.2 \\
-4.1 \\
-4 . \\
-4 . \\
-3.9 \\
-3.9 \\
-3.8 \\
-3.8 \\
-3.7 \\
-3.7 \\
-3.6 \\
-3.6 \\
-3.5 \\
-3.5 \\
-3.4 \\
-3.4 \\
-3.3 \\
-3.3 \\
-3.2 \\
-3.2 \\
-3.1 \\
-3.1 \\
-3 . \\
-3.9 \\
-2.9 \\
-2.9 \\
-2.8 \\
-2.8\end{array}$ & $\begin{array}{l}0 \\
0 \\
0 \\
0 \\
0 \\
0 \\
0 \\
0 \\
0 \\
0 \\
0 \\
0.42819 \\
0 \\
0.682448 \\
0 \\
0.859581 \\
0 \\
1.00228 \\
0 \\
1.12474 \\
0 \\
1.23418 \\
0 \\
1.33523 \\
0 \\
1.43156 \\
0 \\
1.52664 \\
0 \\
1.62467 \\
3 . \\
1.73205 \\
2.78408 \\
1.86249 \\
2.4854 \\
2.07431\end{array}$ & $\begin{array}{l}5 \\
4.9 \\
4.8 \\
4.7 \\
4.6 \\
4.5 \\
4.4 \\
4.3 \\
4.2 \\
4.1 \\
4 . \\
4.02285 \\
3.9 \\
3.95926 \\
3.8 \\
3.89601 \\
3.7 \\
3.83335 \\
3.6 \\
3.77161 \\
3.5 \\
3.71122 \\
3.4 \\
3.65279 \\
3.3 \\
3.59713 \\
3.2 \\
3.54551 \\
3.1 \\
3.49993 \\
4.24264 \\
3.4641 \\
4.02009 \\
3.44657 \\
3.74396 \\
3.48465\end{array}$ & $\begin{array}{l}180 \\
180 \\
180 \\
180 \\
180 \\
180 \\
180 \\
180 \\
180 \\
180 \\
180 \\
173.89 \\
180 \\
170.074 \\
180 \\
167.254 \\
180 \\
164.843 \\
180 \\
162.65 \\
180 \\
160.576 \\
180 \\
158.559 \\
180 \\
156.549 \\
180 \\
154.495 \\
180 \\
152.342 \\
135 . \\
150 . \\
136.168 \\
147.29 \\
138.406 \\
143.468\end{array}$ & $\begin{array}{l}8.125 \\
7.85913 \\
7.616 \\
7.39628 \\
7.20092 \\
7.03125 \\
6.88914 \\
6.77719 \\
6.699 \\
6.6597 \\
6.66667 \\
6.2111 \\
6.73075 \\
5.55803 \\
6.8685 \\
4.96734 \\
7.1062 \\
4.43508 \\
7.488 \\
3.95731 \\
8.09375 \\
3.53007 \\
9.08367 \\
3.14934 \\
10.8323 \\
2.81095 \\
14.464 \\
2.51041 \\
25.6034 \\
2.2425 \\
8.34702 \mathrm{E}-7 \\
2 . \\
0.484331 \\
1.769 \\
0.990073 \\
1.48993\end{array}$ \\
\hline
\end{tabular}


TABLE I

\section{(continued)}

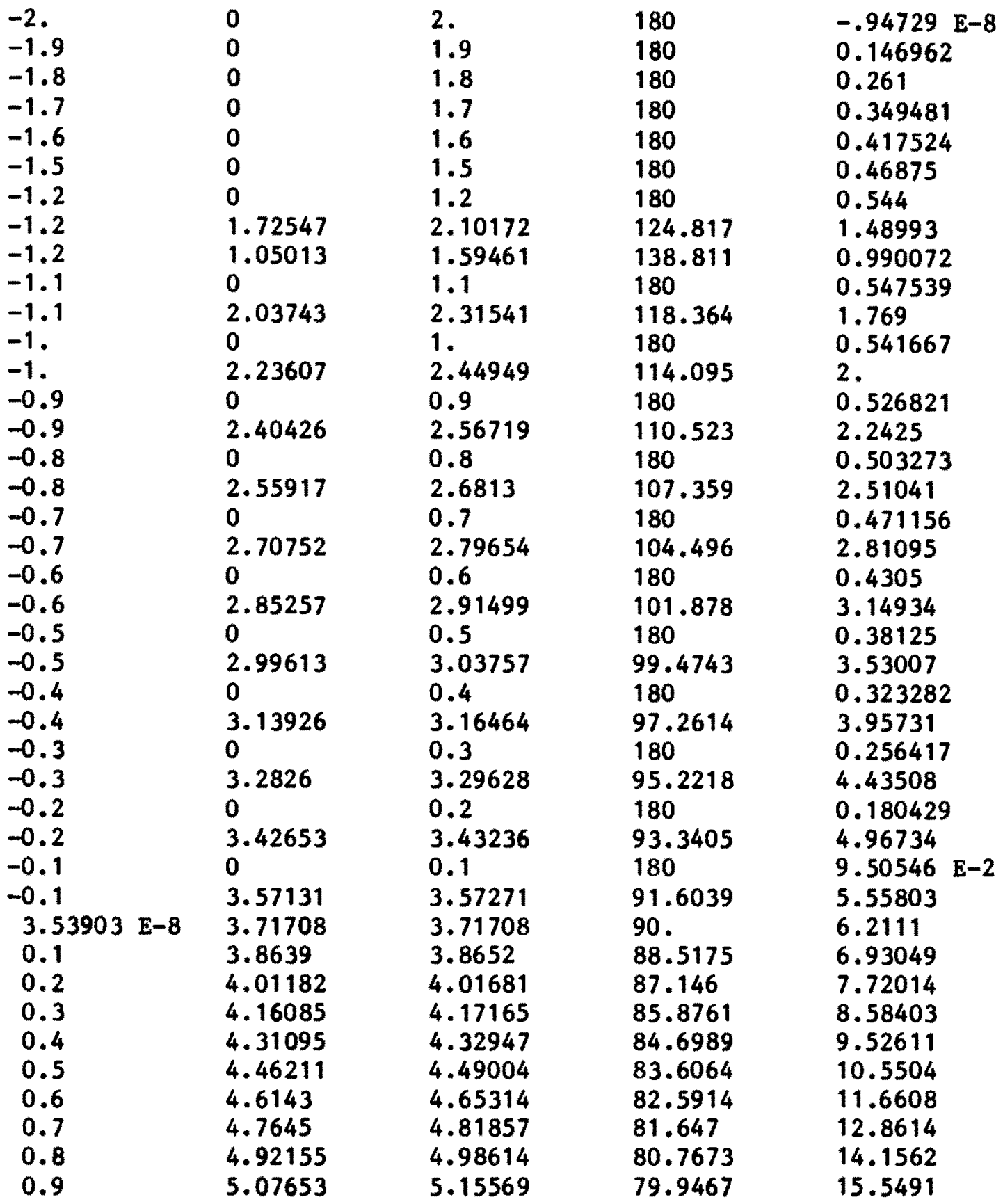

RUN TIME: 3.32 SECS.

READY 
10 DATA $1,12,36$

20 DATA $4,1,8,30,36,0$

30 DATA $-5,1,0.1$

The output of the program, given in TABLE I, is used to draw the complete root locus diagram shown in figure 4.

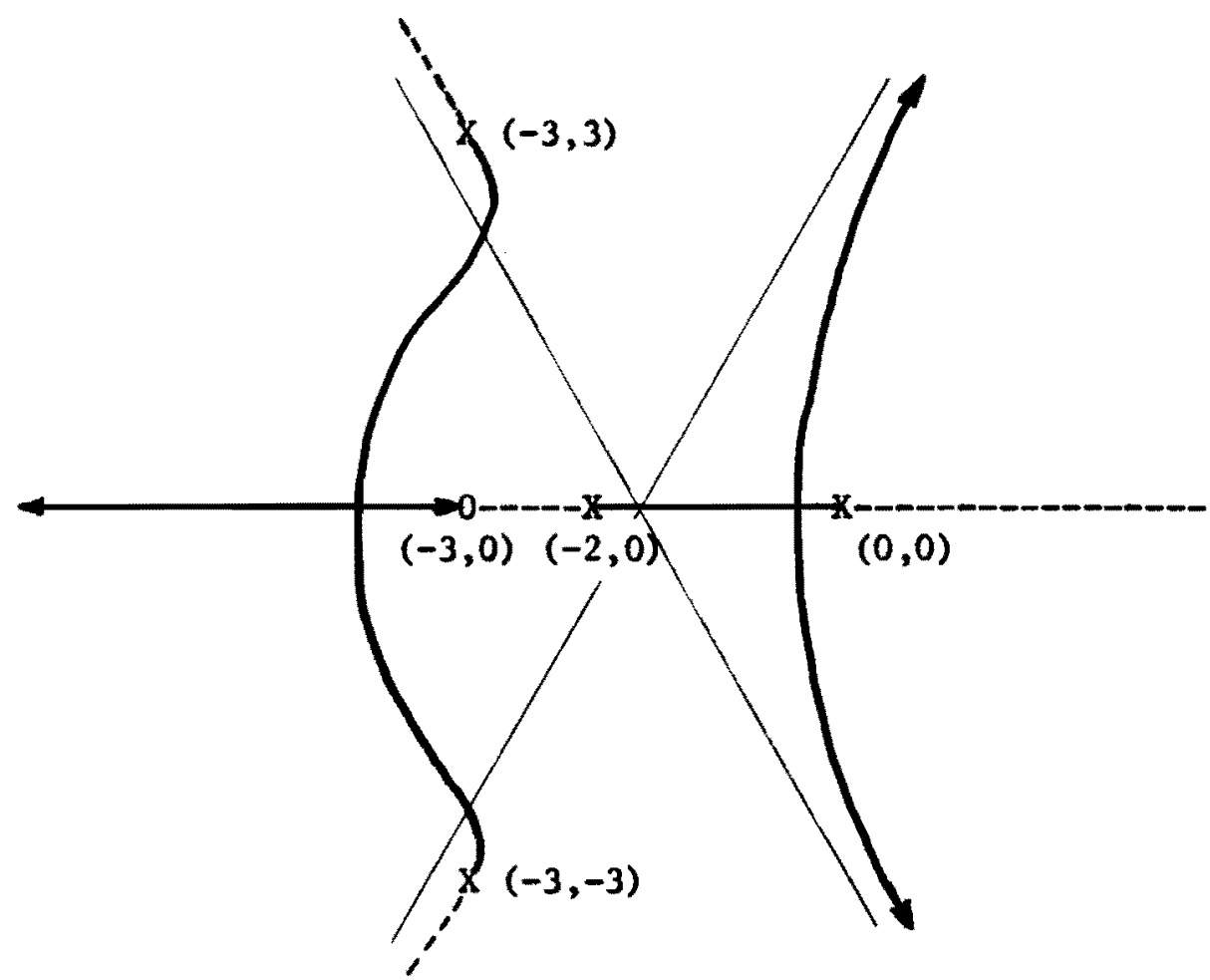

Figure 3. An approximate root locus for the transfer function $\mathrm{GH}=\frac{12 \mathrm{~K}(\mathrm{~s}+3)}{\mathrm{s}\left(\mathrm{s}^{2}+6 \mathrm{~s}+18\right)(\mathrm{s}+2)}$. 


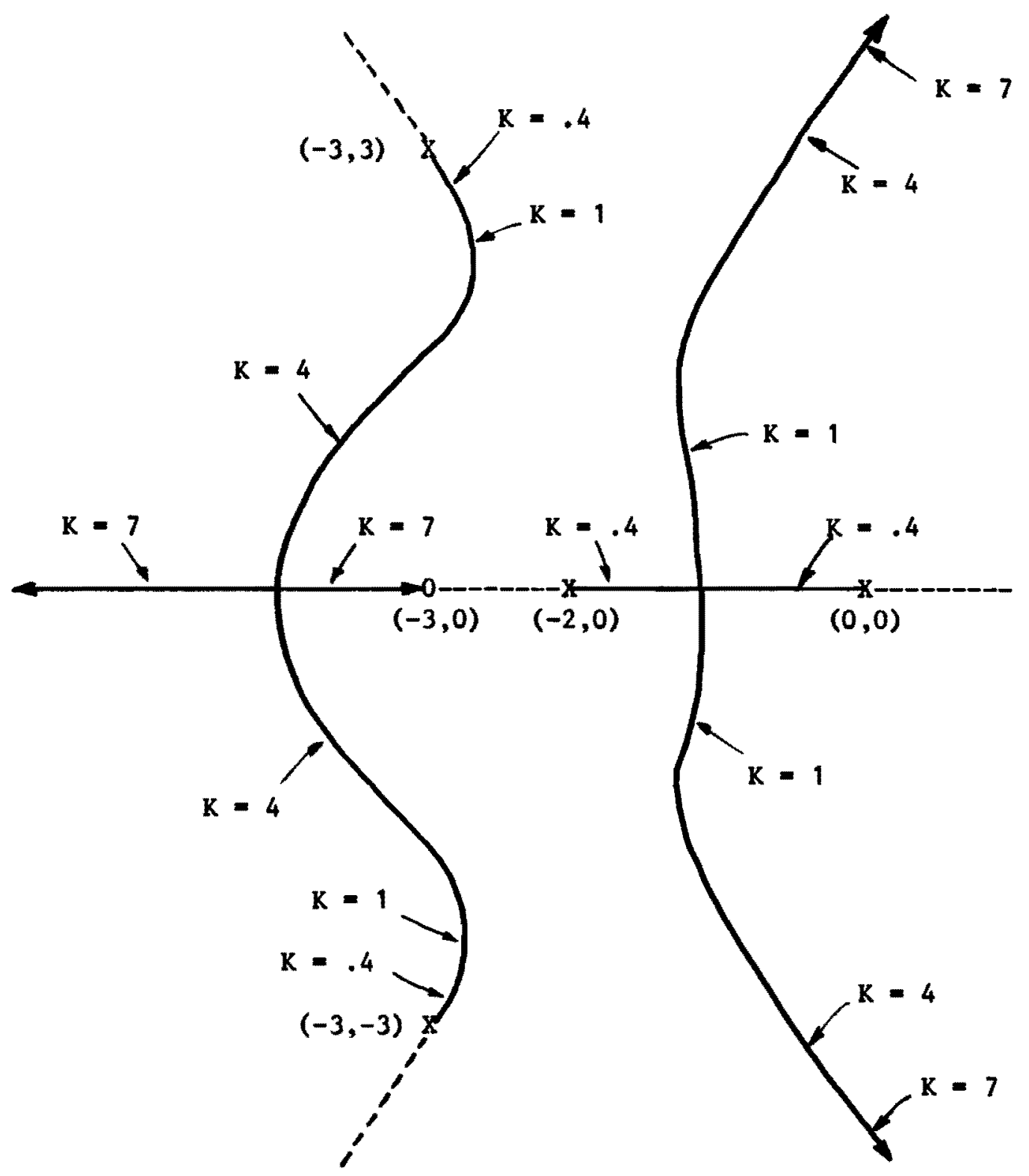

Figure 4. The root locus for $\mathrm{GH}=\frac{12 \mathrm{~K}(\mathrm{~s}+3)}{\mathrm{s}(\mathrm{s}+2)\left(\mathrm{s}^{2}+6 s+18\right)}$. 


\section{CHAPTER IV}

\section{AN ANALYTIC METHOD}

It 18 possible for cases in which the number of poles and zeros is small ( $81 x$ or $1 \mathrm{es}$ ) to determine analytically an explicit equation wich defines the root locus. The process derives directly from the method of CHAPTER II by treating $\sigma$ as a variable. The quadratic formula can be used to find the roots of $D(\omega)$ when mtn is equal to five or six. For lesser order problems, analytic geometry w11l give an Insight into the solution. An example of a fifth order problem is given In this chapter. A table of solutions for most problems of order four and less is given with an example of the methods used in deriving the table. Some examples are given to 1llustrate the use of the table in solving problems.

An Example of the Analytic Method

Consider the transfer function $\mathrm{GH}=\mathrm{K}(\mathrm{s}+3) /\left(\mathrm{s}^{4}+8 \mathrm{~s}^{3}+37 \mathrm{~s}^{2}+50 \mathrm{~s}\right)$. Let $\sigma$ be replaced by $x$ and let $x$ become a variable. To determine the root locus for this transfer function, follow the steps of the method given in CHAPTER II as follows:

Step 1: Find the coefficients of $G(8+x) H(s+x)$. The numerator is shifted as follows:

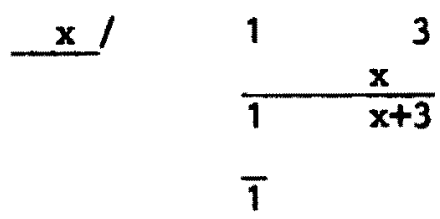

Thus $a_{0}=x+3$ and $a_{1}=1$. The denominator is handled similarly: 
$\times / 18$

37

50

0

$x \quad x^{2}+8 x \quad x^{3}+8 x^{2}+37 x \quad x^{4}+8 x^{3}+37 x^{2}+50 x$

$1 \quad x+8 \quad x^{2}+8 x+37 \quad x^{3}+8 x^{2}+37 x+50 \quad x^{4}+8 x^{3}+37 x^{2}+50 x$

$x \quad 2 x^{2}+8 x \quad 3 x^{3}+16 x^{2}+37 x$

$12 x+8 \quad 3 x^{2}+16 x+37 \quad 4 x^{3}+24 x^{2}+74 x+50$

$x \quad 3 x^{2}+8 x$

$13 x+8 \quad 6 x^{2}+24 x+37$

$\mathbf{x}$

$14 x+8$

1

1

Thus $b_{0}=x^{4}+8 x^{3}+37 x^{2}+50 x, b_{1}=4 x^{3}+24 x^{2}+74 x+50, b_{2}=6 x^{2}+24 x+37$, $b_{3}=4 x+8$ and $b_{4}=1$.

Step 2: Find the coefficients of $D(\omega)$. From equation 2.4,

$d_{1}=-(x+3)\left(4 x^{3}+24 x^{2}+74 x+50\right)+\left(x^{4}+8 x^{3}+37 x^{2}+50 x\right)$

$=-\left(3 x^{4}+28 x^{3}+109 x^{2}+222 x+150\right)$ and

$d_{3}=(x+3)(4 x+8)-\left(6 x^{2}+24 x+37\right)=-\left(2 x^{2}+4 x+13\right)$. Also $d_{5}=1$.

Step 3: Solve for the roots of $D(\omega)$ by setting $D(\omega)=0$.

$$
\omega^{5}-\left(2 x^{2}+4 x+13\right) \omega^{3}-\left(3 x^{4}+28 x^{3}+109 x^{2}+222 x+150\right) \omega=0
$$

Removing the zero root and using the quadratic formula gives

$\omega=0$ and

$\omega^{2}=\left(x^{2}+2 x+6.5\right) \pm 2 \sqrt{x^{4}+8 x^{3}+31.5 x^{2}+62 x+48.0625}$

Equation 4.2 gives an explicit relation between $\omega$ and $x$ for all solutions of equation 2.1 . Note that if the descriminant of equation 4.2 is negative, there are no solutions. If the descriminant is posItive, there may be either two or four solutions depending on the 
relative magnitudes of the elements of the equation. Setting $\omega=0$ in equation 4.1 gives a polynomial the roots of which are the points where the locus crosses the real axis. In this case they are -4.20588 and -1.17395 . The root locus diagram for this problem is shown in figure 5.

The General Analytic Solution

For problems having less than five poles and zeros a solution can be found such that the root locus diagram is completely defined in terms of the system parameters. Combining analytic geometry with the methods above is the key.

Consider the case where $\mathrm{GH}$ has a zero at $8=c$ and a pair of complex conjugate poles at $s=u+j v$ and $s=u-j v$. The expression for the transfer function is

$$
\mathrm{GH}=\frac{K(s-c)}{s^{2}-2 u s+u^{2}+v^{2}}
$$

Following the procedure as before, $a_{1}=1$ and $a_{0}=x-c$. Also $b_{2}=1$, $b_{1}=2(x-u)$ and $b_{0}=x^{2}-2 u x+u^{2}+v^{2}$. Then $D(\omega)=\omega^{3}+\left(-x^{2}+2 c x-2 u c+u^{2}+v^{2}\right) w$ Setting $D(\omega)=0$ leads to the solutions

and

$$
\omega=0
$$

$\omega^{2}+(x-c)^{2}=(u-c)^{2}+v^{2}$

From analytic geometry this is recognized as the equation for a circle with its center at $c$ and a radius equal to the square root of $(u-c)^{2}+v^{2}$. Note that the circle passes through the points $u+j v$ and $u-j v$ as expected. The circle is also symetrical with respect to the real axis. The value of $\mathrm{K}$ can be determined most easily by substitution into 

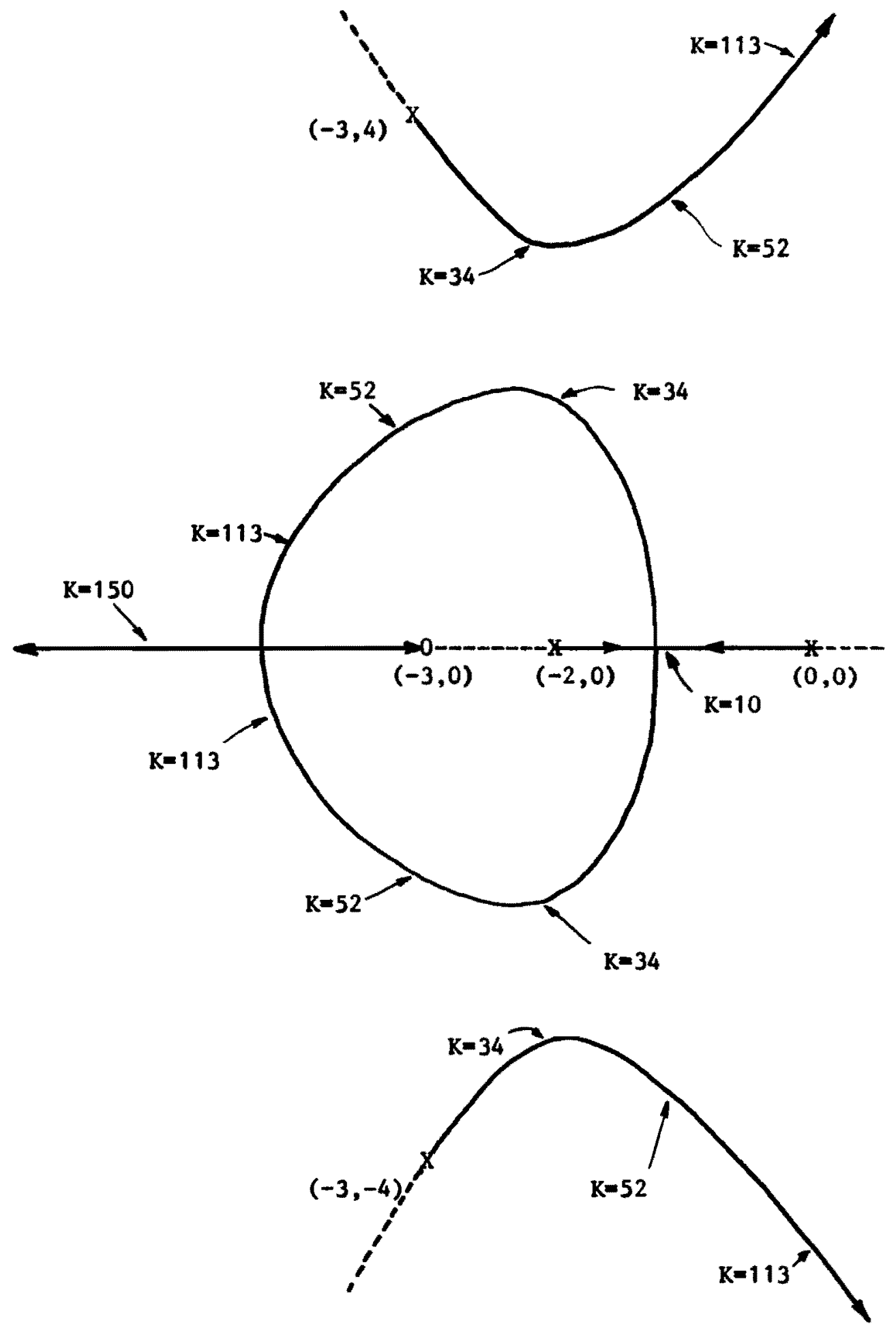

Figure 5. The root locus plot for $G H=\frac{K(s+3)}{s(s+2)\left(s^{2}+68+25\right)}$ 
equation 4.3. That is, for $\omega=0,8=x$ and from equation 2.1,

$$
G H=\frac{K(x-c)}{x^{2}-2 u x+u^{2}+v^{2}}=-1
$$

or $K=\left(x^{2}-2 u x+u^{2}+v^{2}\right) /(c-x)$. For points on the circle $s=x+j \omega$ where $x$ and $\omega$ are related by equation 4.4 . Then

$$
\begin{aligned}
K & =\frac{(x+j \omega)^{2}-2 u(x+j \omega)+u^{2}+v^{2}}{c-x-j \omega} \\
& =\frac{x^{2}+2 j x \omega-\omega^{2}-2 u x-2 j u \omega+u^{2}+v^{2}}{c-x-j \omega} \\
& =\frac{\left[(x-u)^{2}+v^{2}-\omega^{2}+2 j(x-u) \omega(c-x+j \omega)\right.}{(c-x-j \omega)(c-x+j \omega)} \\
& =\frac{\left[(x-u)^{2}+v^{2}-\omega^{2}\right](c-x)-2 \omega^{2}(x-u)}{(c-x)^{2}+\omega^{2}} .
\end{aligned}
$$

The Imaginary part is equal to zero by the derivation of equation 4.4 . The denominator is equal to the square of the radius of the circle. By substituting equation 4.4 into equation 4.5 ,

$$
\begin{aligned}
K & =\frac{\left\lfloor(x-u)^{2}+x^{2}-2 c x+2 u c-u^{2}\right\rfloor(c-x)-2 \omega^{2}(x-u)}{r^{2}} \\
& =\frac{2\left(x^{2}-u x-c x+u c\right)(c-x)-2 \omega^{2}(x-u)}{r^{2}} \\
& =\frac{-2(x-u)(x-c)^{2}-2 \omega^{2}(x-u)}{r^{2}} \\
K & =-2(x-u) .
\end{aligned}
$$

This is the equation for the gain constant for points on the circle. The equation is symmetrical with respect to the real axis since the Bame relation obtains when the substitution $s=x-j \omega$ is made.

Table II is presented as a summary of the solutions for root loci when $m+n$ is less than five. The table was developed using the 
techniques above. The entries are coded for easy reference. The first number is the total number of poles and zeros or $m+n$. The second number is the number of complex roots of the transfer function. The third number is the total number of poles. The code for the example on page 33 is 3.2 .2 . In the diagrams dashed lines will be used to denote portions of the locus for which $\mathrm{K}$ is negative. Solid 1 ines will be used where $K$ is positive. The arrows point in the direction of increasing values of $\mathrm{K}$. The real part of solution points will be denoted by $\sigma$ since the equations now will refer to a general relationship between $\sigma$ and $\omega$ for points in the 8-plane.

The table contains entries for which the number of poles is greater than the number of zeros. If the transfer function has an equal number of poles and zeros, and any of the roots are complex, they are listed as poles. This does not limit the generality of the table, however. For example, let $\mathrm{GH}=\mathrm{k}\left(\mathrm{s}^{2}-2 \mathrm{us}+\mathrm{u}^{2}+\mathrm{v}^{2}\right)$. For this transfer function m 18 greater than $n$. The root locus can be found by using the dual of entry 2.2.2. The dual 18 defined as follows: Replace all zeros by poles and poles by zeros; invert all equations concerning the gain constant $K$; reverse the direction of all arrows. Figure $6 a$ is the root locus for the transfer function above.

As a second example let $G H=K\left(s^{2}+6 s+34\right) / s(s+1)$. Since the zeros are complex the solution must be found from the dual of entry 4.2.2. The solution 18 shown in figure $6 \mathrm{~b}$. On the axis $K=-\sigma(\sigma+1) /\left(\sigma^{2}+6 \sigma+34\right)$. On the circle $K=-(2 \sigma+1) / 2(\sigma+3)=$ $-(\sigma+.5) /(\sigma+3)$. 


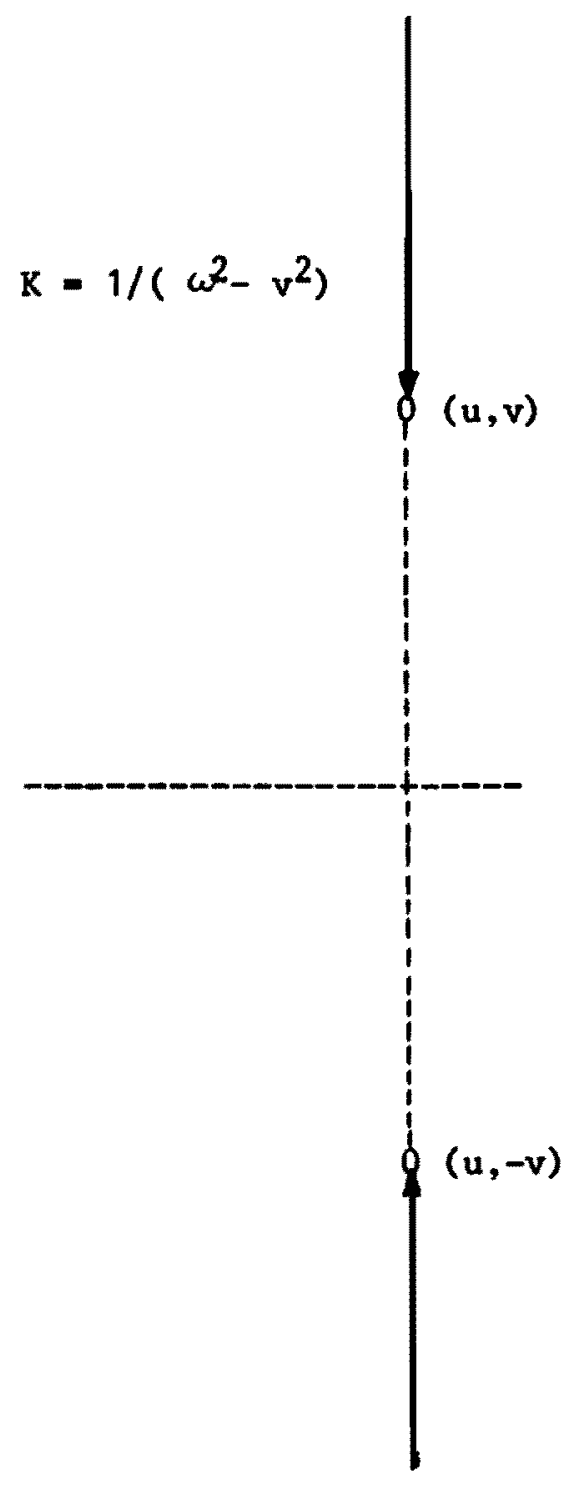

a.

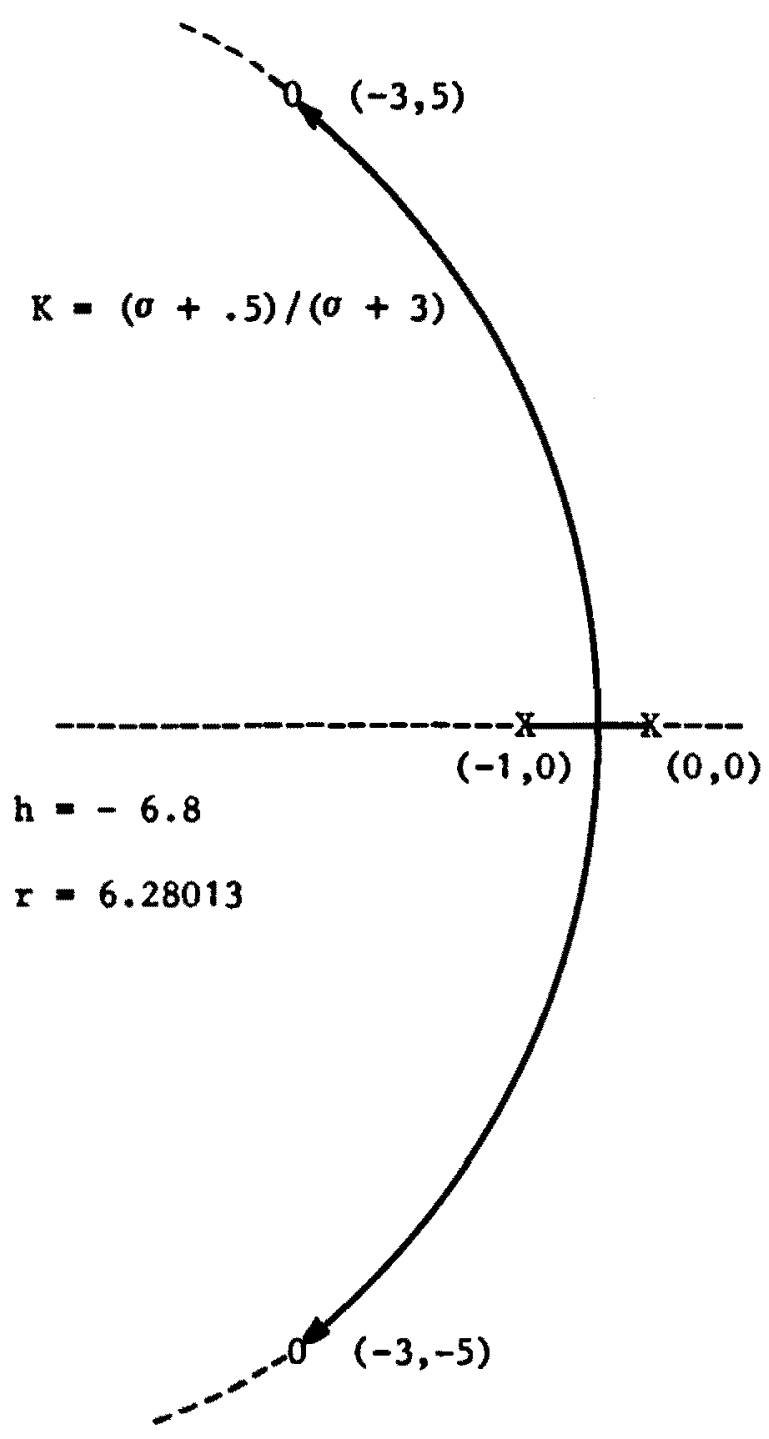

b.

Figure 6. a. The root locus for $G H=k\left(s^{2}-2 u s+u^{2}+v^{2}\right)$. b. The root locus for $\mathrm{GH}=K\left(\mathrm{~s}^{2}+6 \mathrm{~s}+34\right) / \mathrm{s}(\mathrm{s}+1)$. 
TABLE II

ROOT LOCI FOR LOW ORDER SYSTEMS

CODE : 1.0 .1

TRANSFER FUNCTION: $\mathrm{GH}=\mathrm{K} /(\mathrm{s}-\mathrm{a})$

$D(\omega): \quad \omega=0$

REMARKS: For all $\sigma$ the locus is the real axis. $K=-(\sigma-a)$.

Thus $\mathrm{K}$ is positive to the left of $a$ and $K$ is negative to the right of a.

DIAGRAM:

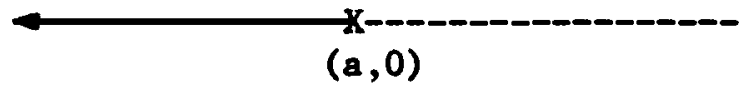

CODE: 2.0 .1

TRANSFER FUNCTION: $\mathrm{GH}=\mathrm{K}(\mathrm{s}-\mathrm{a}) /(\mathrm{s}-\mathrm{b})$

$D(\omega): \quad \omega(a-b)=0$

REMARKS: For all $\sigma$ the locus is on the real axis. $K$ is positive for $b<\sigma<a$ or for $a<\sigma<b$ since $K=(b-\sigma) /(\sigma-a)$.

DIAGRAM:

1). $a>b$

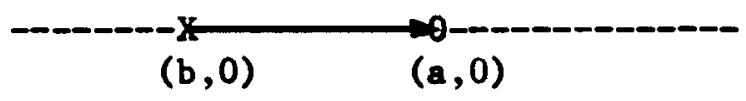

2). $a<b$

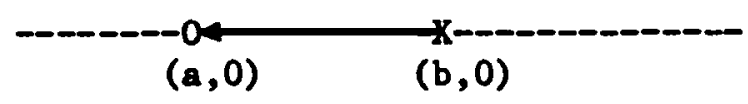


TABLE II (Continued)

CODE: 2.0 .2

TRANSFER FUNCTION: $\quad \mathrm{GH}=\mathrm{K} /(\mathrm{s}-\mathrm{a})(\mathrm{s}-\mathrm{b})$

$D(\omega): \quad \omega(a+b-2 \sigma)=0$

REMARKS: If $\sigma=(a+b) / 2, \omega$ can assume any value. If not, $\omega=0$.

This means that the locus includes the real axis and a vertical Iine which intersects the real axis at $(a+b) / 2$. On the axis $K=(a-\sigma)(\sigma-b)$. On the vertical line $K=\frac{(a-b)}{4}+\omega^{2}$. $K$ is positive on the vertical line and for $a<\sigma<b$ or $b<\sigma<a$. DIAGRAM:

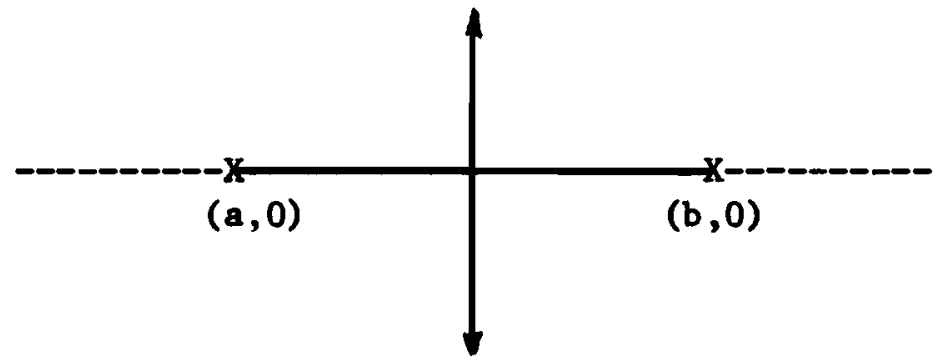

CODE: 2.2 .2 .

TRANSFER FUNCTION: $G H=K /\left(s^{2}-2 u s+u^{2}+v^{2}\right)$

$D(\omega): \quad 2(\sigma-u) \omega=0$

REMARKS: If $\sigma=u, \omega$ can assume any value. If not, $\omega=0$. The locus includes the real axis and a vertical line which intersects the real axis at $u$. On the axis $K=-\left(\sigma^{2}-2 u \sigma+u^{2}+v^{2}\right)$ which is always negative. For the vertical line $K=\omega^{2}-v^{2}$ which is positive for $\omega^{2}>v^{2}$.

DIAGRAM:

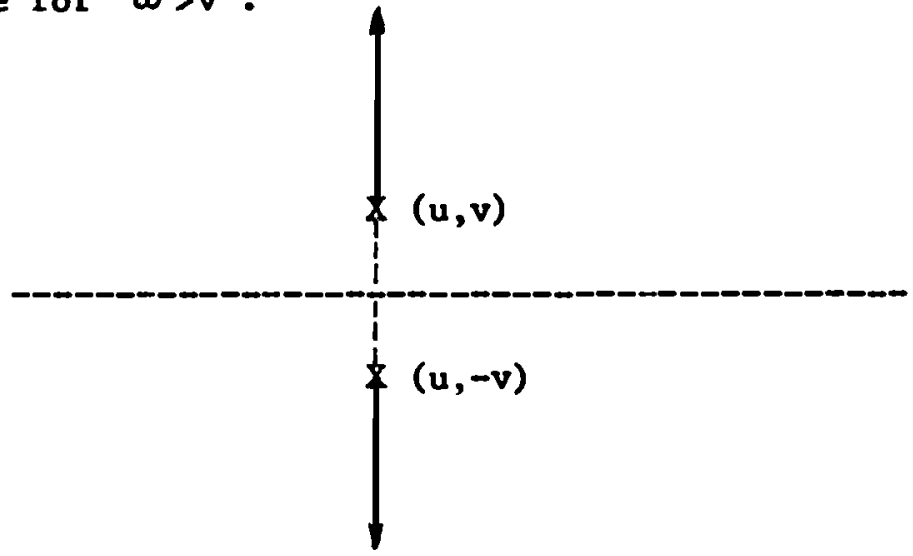


TABLE II (Continued)

CODE: 3.0 .2 .

TRANSFER FUNCTION: $\mathrm{GH}=\mathrm{K}(\mathrm{B}-\mathrm{c}) /(\mathrm{B}-\mathrm{a})(\mathrm{s}-\mathrm{b})$

$D(\omega): \quad \omega^{3}+\left(\sigma^{2}-2 c \sigma-a b+a c+b c\right) \omega=0$

1). $\omega=0$

2). $a^{2}+\sigma^{2}-2 c \sigma-a b+a c+b c=0$

REMARKS: The first equation defines the real axis. The second equation defines a circle with its center at $c$ and a radius which is the square root of $c^{2}+a b-a c-b c$. The polarity of $K$ depends on the relative positions of the poles and zero. On the axis $K=(\sigma-a)(\sigma-b) /(c-\sigma)$. On the circle $K=a+b-2 \sigma$.

DIAGRAM: 1). $c<b<a$

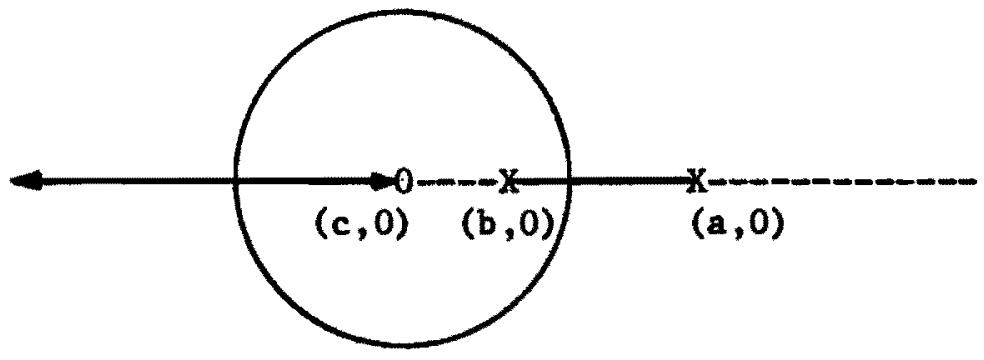

2). $b<c<a$

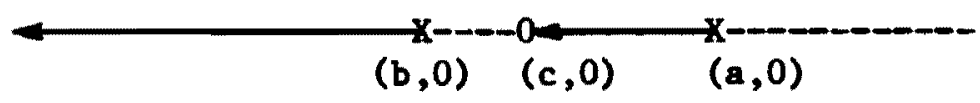

3). $a<b<c$

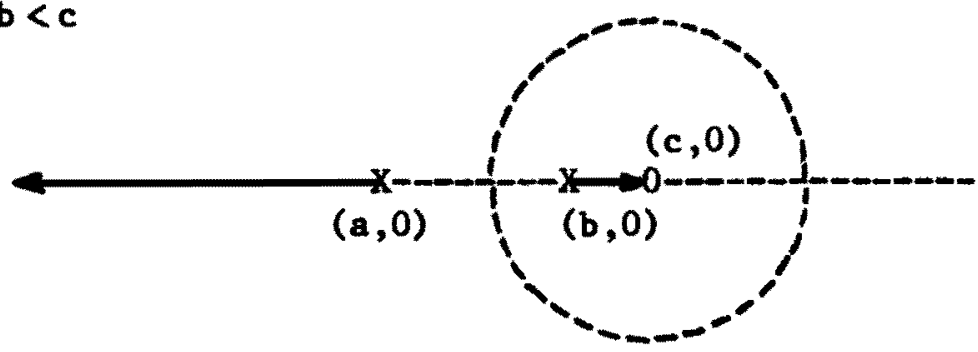


TABLE II (Continued)

CODE: $\quad 3 \cdot 0.3$.

TRANSFER FUNCTION: $G H=K /(8-a)(8-b)(8-c)$ where $a<b<c$

$D(\omega):-\omega^{3}+\left[30^{2}-2 \sigma(a+b+c)+a b+a c+b c\right] \omega=0$

1). $\omega=0$

2). $3(\sigma-h)^{2}-u^{2}=r^{2}$

where $h=(a+b+c) / 3$ and $r^{2}=3 h^{2}-(a b+a c+b c)$

REMARKS: The first equation defines the real axis. The second equation defines an hyperbola with its center at $(h, 0)$ and with assymptotes at sixty degrees from the real axis. On the real axis $K=-(\sigma-a)(\sigma-b)(\sigma-c)$ which is positive for $\sigma<a$ and for $b<\sigma<c$. For points on the hyperbola it is found that $K=8 \sigma^{3}-24 h \sigma^{2}+2\left(12 h^{2}-r^{2}\right) \sigma+a b c-3 h\left(3 h^{2}-r^{2}\right)$ which is positive for $\sigma>h$ and negative for $\sigma<h$.

DIAGRAM:

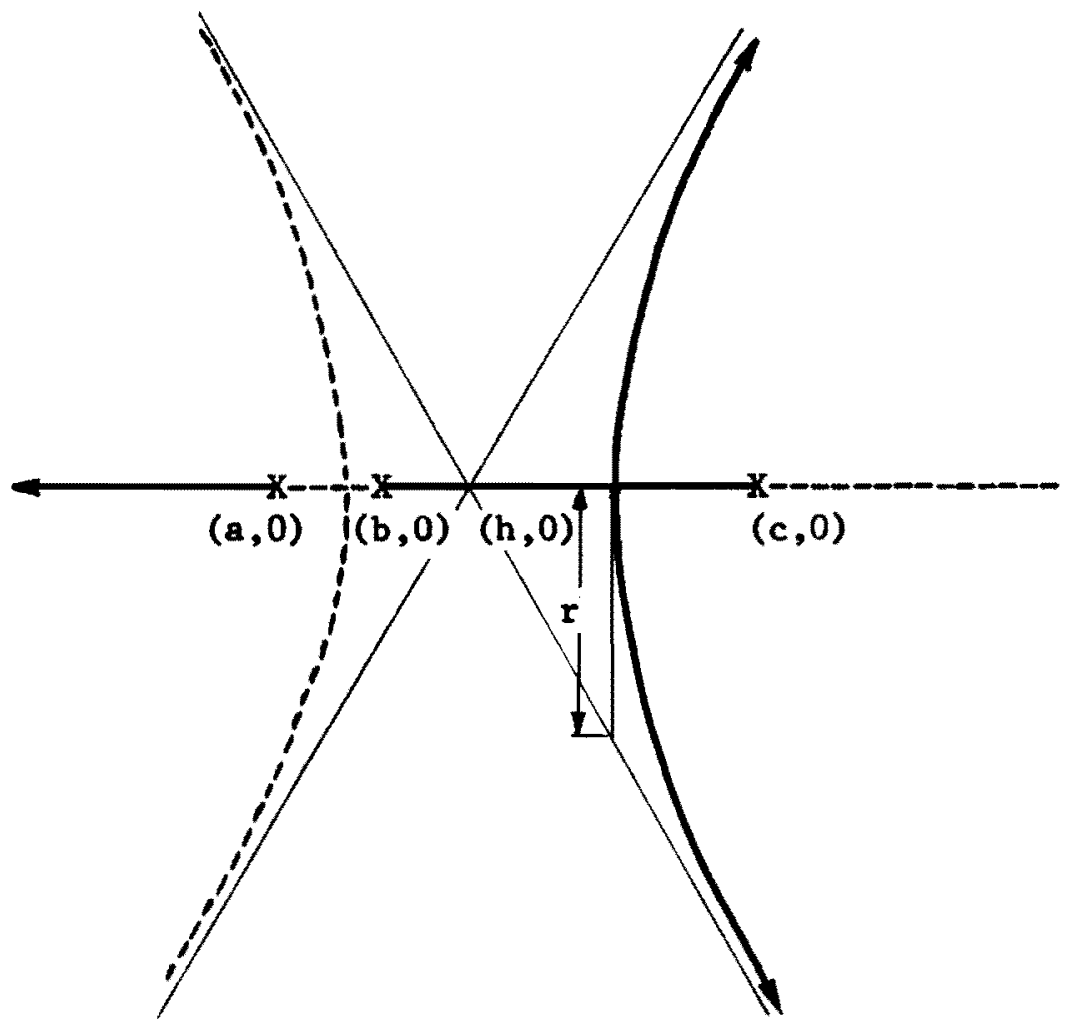


TABLE II (Continued)

CODE: $\quad 3.2 .2$.

TRANSFER FUNCTION: $G H=\frac{K(s-c)}{s^{2}-2 u s+u^{2}+b^{2}}$

$D(\omega): \quad \omega^{3}+\left(\sigma^{2}-2 \sigma o+2 u c-u^{2}-v^{2}\right) \omega=0$

1). $\quad \omega=0$

2). $u^{2}+(\sigma-c)^{2}=(u-c)^{2}+v^{2}$

REMARKS: The first equation defines the real axis. The second equation defines a circle with 1 ts center at $(\sigma-c, 0)$ and a radius squared of $(u-c)^{2}+v^{2}$. On the circle $K=-2(\sigma-u)$ which is positive for $\sigma<u$. $K=-\left(\sigma^{2}-2 v \sigma+u^{2}+v^{2}\right) /(\sigma-c)$ on the axis which is positive for $\sigma<c$.

DIAGRAM:

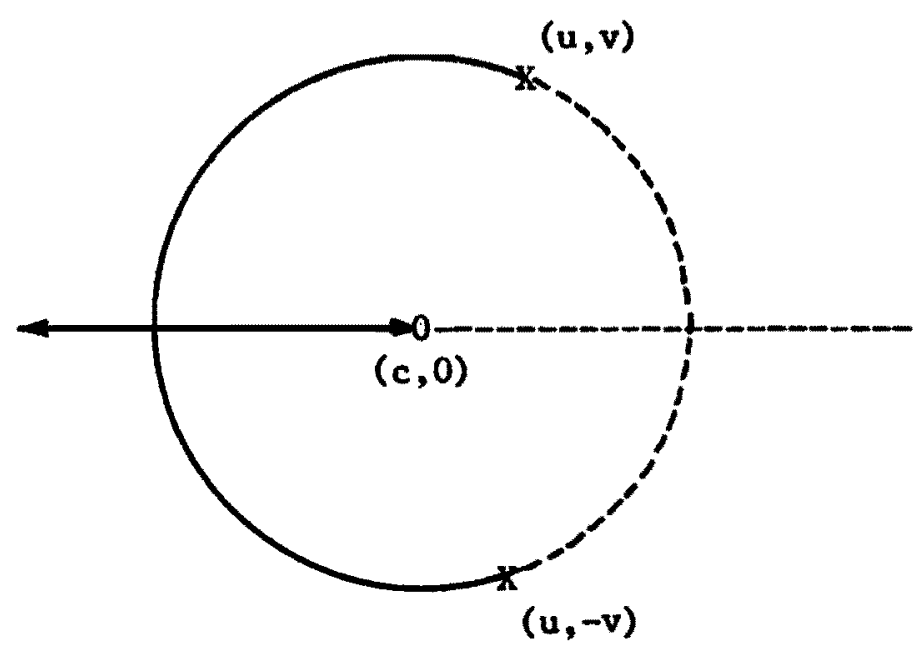


TABLE II (Continued)

CODE: 3.2 .3 .

TRANSFER FUNCTION: $\quad G H=\frac{K}{(s-a)\left(s^{2}-2 u s+u^{2}+v^{2}\right)}$

$D(\omega): \quad-\omega^{3}+\left[30^{2}-2 \sigma(2 u-a)+2 u a+u^{2}+v^{2}\right] \omega=0$

1). $\omega=0$

2). $3(\sigma-h)^{2}-\omega^{2}=r^{2}$

where $h=(2 u+a) / 3$ and $r^{2}=\left[(a-u)^{2} / 3\right]-v^{2}$

REMARKS: The first equation defines the real axis. The second equation defines an hyperbola with its center at $h$ and assymptotes at sixty degrees from the horizontal. On the axis $K=-(\sigma-a)\left(\sigma^{2}-2 v \sigma+u^{2}+v^{2}\right)$ which is positive for $\sigma<a$. On the hyperbola $K=2(\sigma-u)\left[(20-a)^{2}+(a-u)^{2}+v^{2}-a^{2}\right]$ which 18 positive for $\boldsymbol{\sigma}>\mathrm{u}$.

\section{DIAGRAM:}
1). $r^{2}<0$
2). $r^{2}>0$
3). $x^{2}=0$
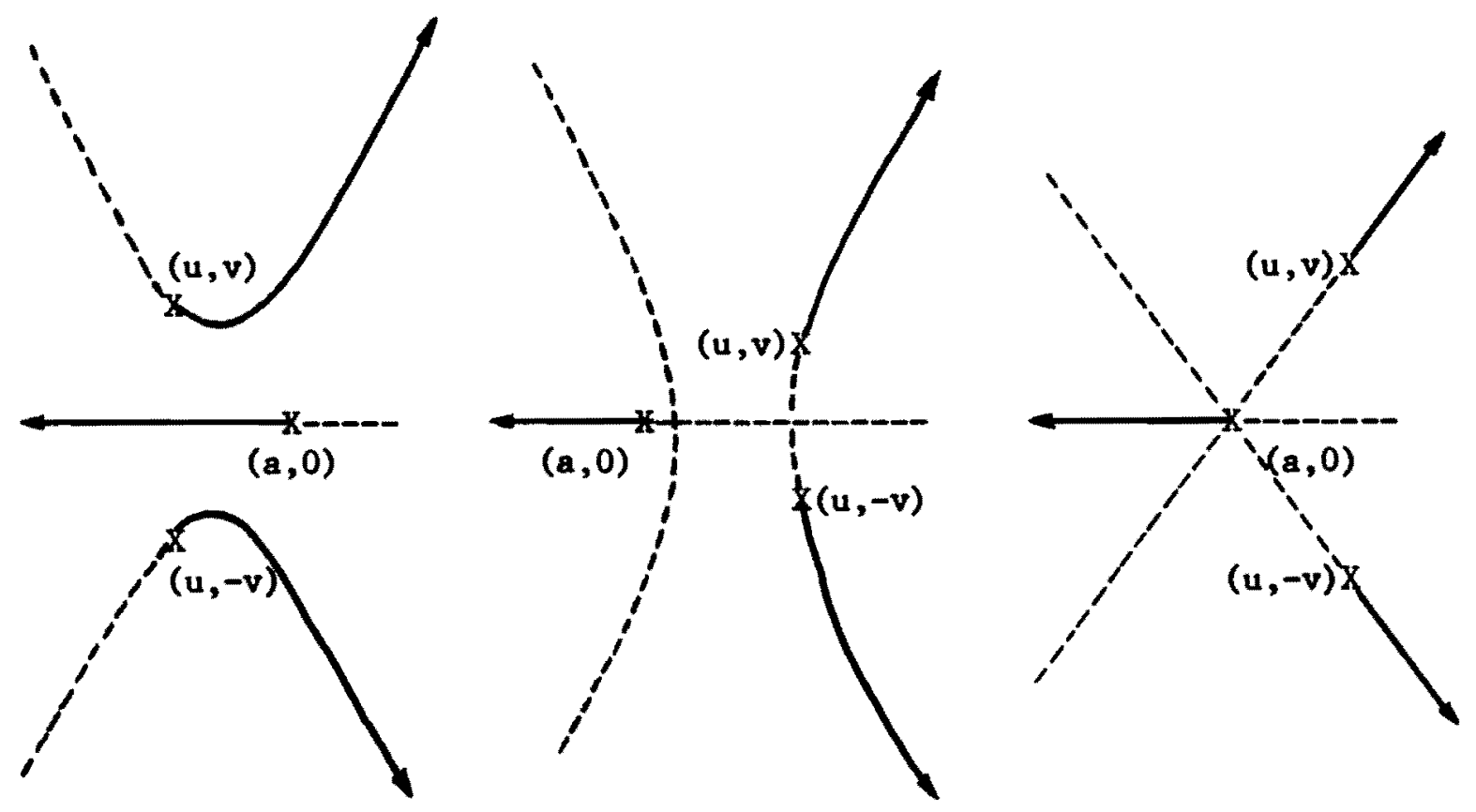
CODE: $\quad 4 \cdot 0.2$

TRANSFER FUNCTION: $\quad G H=\frac{(B-c)(s-d)}{(s-a)(8-b)}$ where $a>b$ and $c>d$

$D(\omega): \quad(a+b-c-d) \omega^{3}+\left[(a+b-c-d) \sigma^{2}-2(a b-c d) \sigma+a b(c+d)-c d(a+b)\right] \omega=0$

1). $\omega=0$

2). $\omega^{2}+(\sigma-h)^{2}=r^{2}$

where $h=(a b-c d) /(a+b-c-d)$

and $r^{2}=h^{2}+\frac{c d(a+b)-a b(c+d)}{a+b-c-d}$

REMARKS: The first equation defines the real axis. The second equation defines a circle with 1 ts center at $(h, 0)$ and radius $r$. On the real axis $K=-\frac{(\sigma-a)(\sigma-b)}{(\sigma-c)(\sigma-d)}$ which may be positive or negative depending upon the relative positions of the poles and zeros. On the circle $k=-\frac{20-(a+b)}{2 \sigma-(c+d)}$.

DLAGRAM:

1). $\mathbf{d}<\mathrm{c}<\mathrm{b}<\mathrm{a}$

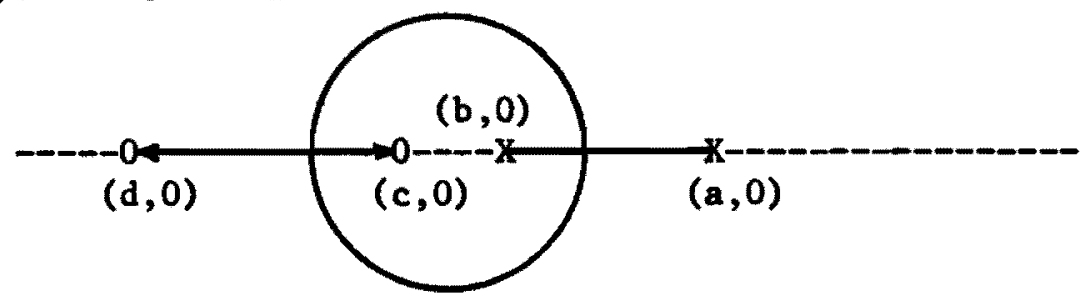

2). d $<$ b $<$ c $<$ a

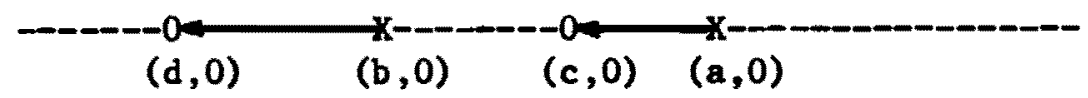

3). b $<$ d $<$ c $<$ a

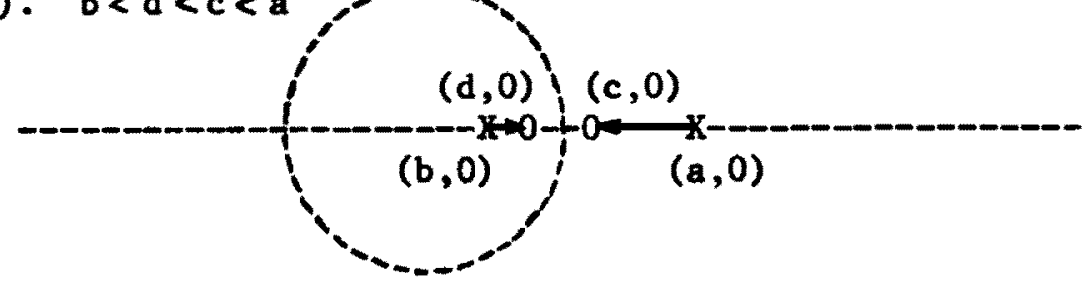


TABLE II (Continued)

CODE: 4.2 .2 .

TRANSFER FUNCTION: $G H=\frac{K(s-c)(s-d)}{s^{2}-2 u s+u^{2}+v^{2}}$ where $c<d$

$D(\omega):(2 u-c-d) \omega^{3}+\left[(2 u-c-d) o^{2}-2\left(u^{2}+v^{2}-c d\right) o+\left(u^{2}+v^{2}\right)(c+d)-2 u c d\right] \omega=0$

1). $\omega=0$

2). $\omega^{2}+(\sigma-h)^{2}=r^{2}$

where $h=\frac{u^{2}+v^{2}-c d}{2 u-c-d}$
and $r^{2}=h^{2}+\frac{2 u c d-\left(u^{2}+v^{2}\right)(c+d)}{2 u-c-d}$

REMARKS: The first equation defines the real axis. The second equation defines a circle with its center at $(h, 0)$ and radius $r$. On the real axis $K=-\frac{\sigma^{2}-2 u \sigma+u^{2}+v^{2}}{(\sigma-c)(\sigma-d)}$ and on the circle $K=-\frac{2(\sigma-u)}{2 \sigma-c-d}$. Note that if $\sigma=(c+d) / 2$ the radius is infin1te. In this case the locus is a vertical line at $\sigma=u$ and $K=\frac{4\left(v^{2}-\omega^{2}\right)}{4 \omega^{2}+(d-c)^{2}}$

DIAGRAM:

1).

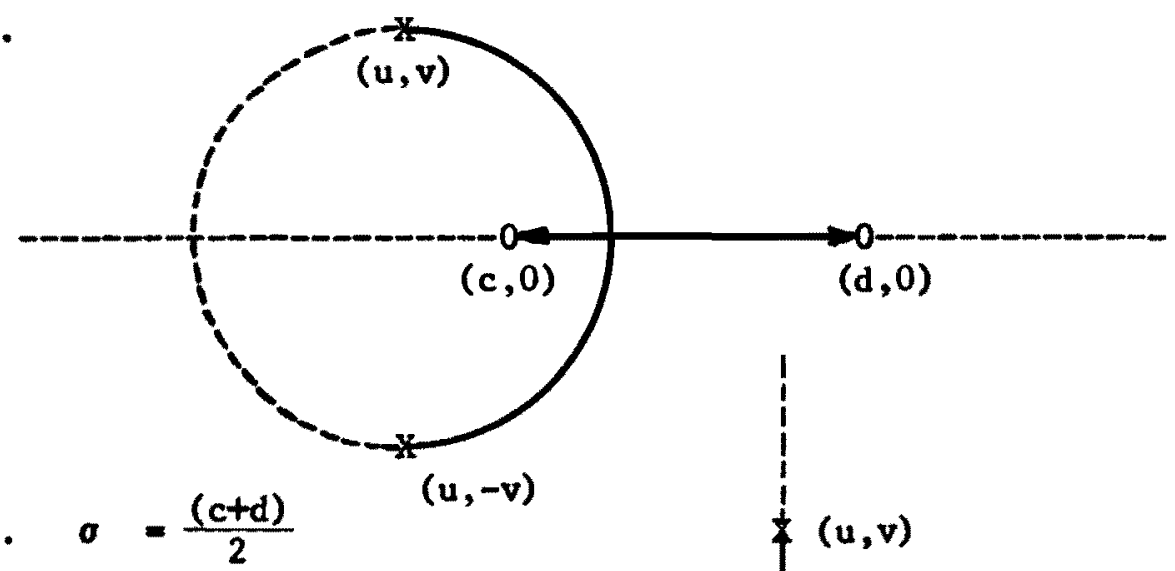

2). $\quad \sigma=\frac{(c+d)}{2}$

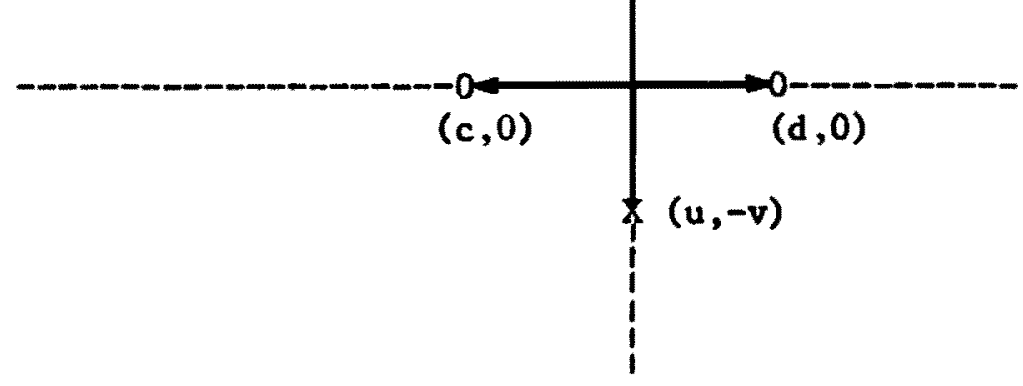


TABLE II (Continued)

CODE: $\quad 4 \cdot 4 \cdot 2$.

TRANSFER FUNCTION: $G \mathrm{GH}=\left(s^{2}-2 u s+u^{2}+v^{2}\right) /\left(s^{2}-2 t s+t^{2}+y^{2}\right)$

$D(\omega): \quad(u-t) \omega^{3}+\left[(u-t) \sigma^{2}-\left(u^{2}+v^{2}-t^{2}-y^{2}\right) \sigma-t\left(u^{2}+v^{2}\right)-u\left(t^{2}+y^{2}\right)\right] \omega=0$

$$
\begin{aligned}
\text { 1). } \omega & =0 \\
\text { 2). } \omega^{2}+(\sigma-h)^{2} & =r^{2} \\
\text { where } h & =\frac{u^{2}+v^{2}-t^{2}-y^{2}}{2(u-t)} \\
\text { and } r^{2} & =h^{2}+\frac{u\left(t^{2}+y^{2}\right)-t\left(u^{2}+v^{2}\right)}{u-t}
\end{aligned}
$$

REMARKS: The first equation defines the real axis. The second equation defines a circle with 1 ts center at $(h, 0)$ and radius $r$. On the real axis $K=-\frac{\sigma^{2}-2 t \sigma+t^{2}+y^{2}}{\sigma 2-2 \sigma^{2}+u^{2}+v^{2}}$. On the circle $K=-\frac{\sigma-u}{\sigma-t}$. When $u=t$ the radius 18 infinite. The locus Is a vertical line at $\sigma=u=t$. On the vertical line $K=-\left(y^{2}-w^{2}\right) /\left(v^{2}-w^{2}\right)$.

DIAGRAM:

1). $t \neq u$

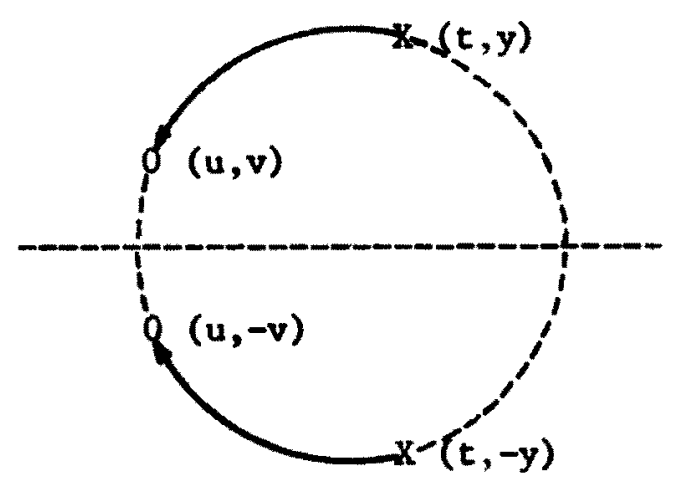

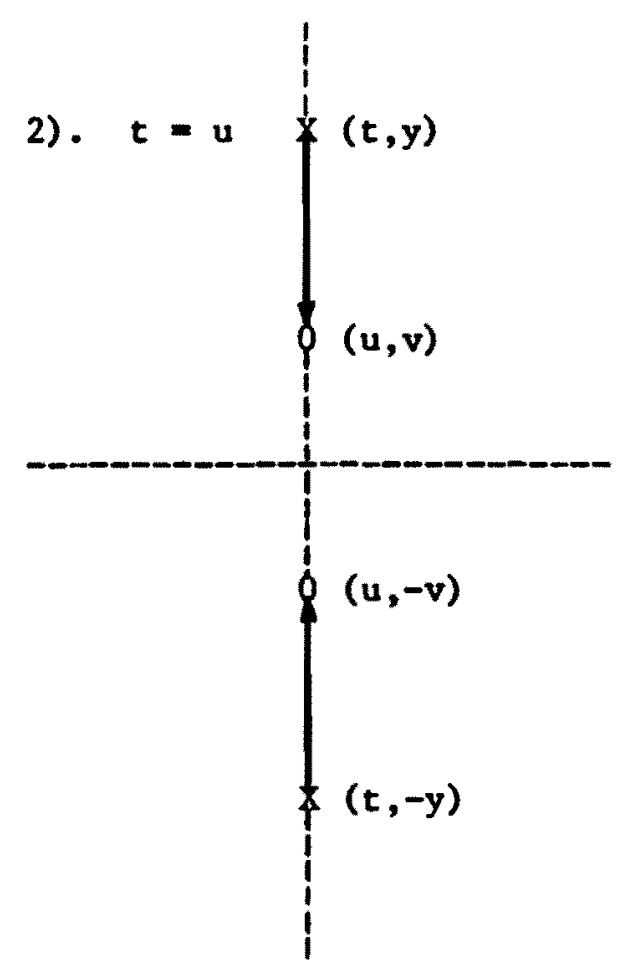


Conclusion

It 18 hoped that the methods developed herein will be of significance to the field of automatic control theory. The procedures have been developed along new lines in order to avold the inherent disadvantages of classical methods. Some classical procedures such as rules for sketching loc1 may be used to advantage. The method developed here does not rely upon these procedures but may be enhanced by them.

The major intent has been to develop an algorithm for solution by digital computers. Previous attempts in this direction involved scanning the entire s-plane by solving an equation which changed sign as a branch of the root locus was crossed. 15 This required a coarse matrix of points in the s-plane with subsequent reduction of the size of the matrix with a corresponding increase in density near areas where the sign changes were noted. This type of attack has many disadvantages. The original matrix must be sufficiently dense to minimize the possibility of skipping over a solution. The accuracy of the method is limitted by the final density of the matrix. To Improve the accuracy many more computations must be made. Furthermore, the value of the system gain varfes greatly in the vicinity of the locus. In many cases this could become a significant factor.

The computer program listed in CHAPTER III does not have these disadvantages. Although the method requires finding a point where a function passea through zero, the function is of one variable and

${ }^{15}$ A. M. Krall, "Algortthm for Generating Root Locus Diagrams," Assn. Computing Machinery, May, 1967, pp. 186-188. 
lends itself to iterative techniques. The accuracy generally depends on the limits of the computer and the accuracy of the input data rather than the algorithm. Storage of solution points is unnecessary. As each point is found, it may be printed and removed from consideration. The accuracy and speed with which problems can be solved gives this method preference over the use of tools or spectal machines for plotting root loci. The example of figure 4 was solved not only with the digital computer but also using a Spirule and an algebraic computer. The Spirule solution required approximately three hours and proved to be about $1 \%$ reliable. The algebraic computer solution took one hour with five percent accuracy. The solution using the digital program required five minutes on a teletype terminal and forty-five minutes of preparation and plotting time.

A further advantage 18 that the factors of the transfer function need not be known. The graphical methods require that the location of each pole and zero be known. This would require that the transfer function be in factored form. Generally the factors are not known and must be determined. This involves efther a separate computer program or a preliminary root locus to find these roots. The program developed in Chapter III does not require that the function be factored. With respect to this also, systems with time delays (denoted by terms of the form $e^{-T s}$ ) are approximated by the equivalent series $1-T s+\frac{T^{2} s^{2}}{2 !}-\ldots 16$ The necessity of factoring an approximate polynomial of this type would

$$
16 \text { Westman, p. } 1084 \text {. }
$$


limit its value. The program can handle this easily without factoring. The number of terms used would not have a major effect on the time taken to solve the problem.

The method has far-reaching possibilitles and the program is fast and reliable. With the ald of plotting routines and oscilloscope interfacing, it may be possible to design aystems in a fraction of the time required using other methods. 
REFERENCES

Cannon, Robert H. Jr. Dynamics of Physical Systems. New York: McGrawH111 Book Company, 1967.

Chang, Chi S. "An Analytical Method for Obtaining the Root Locus with Positive and Negative Gain." IEEE Transactions on Automatic Control, vol. AC-10, no. 1, Jan. 1965.

Evans, W. R. "Graphical Analysis of Control Systems." Trans. AIEE, LXVIII, (1949).

Klagsbrunn, Z, and Y. Wallach. "On Computer Implementation of Analytic Root Locus Plotting." IEEE Transactions on Automatic Control, Dec. 1968.

Kral1, A. M. "Algorithm for Generating Root Locus Diagrams." Assn. Computing Machinery, May, 1967.

Kunz, Kalser S. Numerical Analysis. New York: McGraw-H111 Book Company, 1957.

Morgan, M. L. and J. C. Looney. "Design of the ESIAC Algebraic Computer." IRE Transactions on Electronic Cumputers, vol. EC-10, no. 3, Sept. 1961.

Murphy, Gordon J. Basic Automatic Control Theory. Princeton, N. J.: D. Van Nostrand Company, 1966.

Nielson, Kaj L. College Mathematics. New York: Barnes \& Noble, Inc., 1958.

Pennington, Ralph H. Introductory Computer Methods and Numerical Analys1s, 2nd ed. London: The MacMillan Company, 1970.

Popov, E. P. The Dynamics of Automatic Control Systems, London: Pergamon Press LTD, 1962.

Raven, Francis H. Automatic Control Engineering. New York: McGrawH111 Book Company, 1968.

Salvador1, M. G. and M. L. Baron. Numerical Methods in Engineering. Englewood Cliffs, N. J.: Prentice-Ha11, 1961.

Scheild, Francis. Numerical Analysis. New York: McGraw-H111 Book Company, 1968.

Steiglitz, Kenneth. "An Analytic Approach to Root Loc1." IRE Transactions on Automatic Control, Sept. 1961. 
Stoll, R. R. and E. J. Wong. Linear Algebra. New York: Academic Press, 1968.

Thaler, George J. and Robert G. Brown. Analygis and Design of Feedback Control Systems. New York: McGraw-H111 Book Company, Inc., 1960 .

Truxal, John G. Automat1c Control System Synthes1s. New York: McGrawH111 Book Company, Inc., 1955.

Westman, H. P., ed. Reference Data for Radio Engineers. 4th. ed. New York: American Book-Stratford Press Incorporated, 1967. 